\title{
Anthropogenic Influence on Long-Term Surface Air Temperature Trends: Attribution of Temperature Changes Across East Asia
}

\section{S. Allabakash}

Korea Institute of Civil Engineering and Building Technology

S. Lim ( $\nabla$ slim@kict.re.kr)

Korea Institute of Civil Engineering and Building Technology https://orcid.org/0000-0002-0545-9369

\section{Research Article}

Keywords: Climate change, Detection and attribution, CMIP6, East Asia, Future projections

Posted Date: July 8th, 2021

DOI: https://doi.org/10.21203/rs.3.rs-207433/v2

License: (c) (i) This work is licensed under a Creative Commons Attribution 4.0 International License.

Read Full License 


\section{Attribution of temperature changes across East Asia}

3

4

5

6

7

8

9

10

11

12

13

14

15

16

17

18

19

20 *Corresponding author: S. Lim; 283, Korea Institute of Civil Engineering and Building Technology, Goyang-daero,

21 Ilsanseo-gu, Goyang-si, Gyeonggi-do 10223, South Korea, (slim@ kict.re.kr).

22

S. Allabakash and S. Lim*

Korea Institute of Civil Engineering and Building Technology, Ilsan, Goyang, South Korea

6

(1)

(1)

(1)

10

1

2

3 4

5

6

7

8

9

2 
24 Climate change is an ongoing process impacting ecosystem functions and human health; East Asia (EA) is one of the 25 most vulnerable regions being influenced by such changes. This study examines the long-term variability of surface 26 air temperatures (SATs) across EA using the new Coupled Model Intercomparison Project Phase 6 (CMIP6) datasets.

27 Historical simulations ( $20^{\text {th }}$ century) and future ( $21^{\text {st }}$ century) SAT projections were investigated based on multi-model 28 ensemble simulations. We also demonstrate the contribution of external and natural (NAT) forcings to SAT change. 29 This study mainly focuses the effect of anthropogenic forcings (ANT) on EA climate for a long period (1850-2100). 30 Our simulations show that SAT in EA increased by $0.031{ }^{\circ} \mathrm{C} /$ decade during the period $1850-2014$ owing to combined 31 ANT and NAT ('ALL=ANT+NAT') forcings, while an increase of $0.08{ }^{\circ} \mathrm{C} /$ decade can be attributed to greenhouse 32 gas (GHG) emissions. The ANT forcing rapidly increased after the third industrial revolution (after 1969). 33 Consequently, SAT change accelerated to $0.255^{\circ} \mathrm{C} / \mathrm{decade}$ and $0.268{ }^{\circ} \mathrm{C} / \mathrm{decade}$ owing to ALL and GHG forcings, 34 respectively. Human-induced GHG emissions and land use were the dominant factors driving SAT warming during 35 the study period, and will contribute to substantial future warming trends. Furthermore, optimal fingerprinting method 36 demonstrates the significance of ANT influences on climate change in EA. ANT forcing was clearly detected and 37 distinct from NAT forcing in a two-signal analysis. In a three-signal analysis, GHG was clearly detected for EA region 38 in separation from ANT and NAT influences. The shared socioeconomic pathway emission scenarios (SSP1-2.6, 39 SSP2-4.5, and SSP5-8.5) showed future projections (warming trends) from 2015-2100. This analysis suggests that 40 climate change could be mitigated by restricting anthropogenic factors (especially GHG) and land use/activities in EA.

41 Keywords: Climate change, Detection and attribution, CMIP6, East Asia, Future projections 


\section{Introduction}

The world faces the major challenge of on-going climate change, which greatly impacts socioeconomic and human activities as well as human health (IPCC 2013; Stocker et al. 2014). For example, during the $20^{\text {th }}$ century, average surface air temperatures (SATs) have increased by $0.6{ }^{\circ} \mathrm{C}$ worldwide (IPCC 2013; Stocker et al. 2014). Many authors have investigated the effects of external forcing on mean temperatures at global and regional scales, with increases primarily attributed to anthropogenic greenhouse gas (GHG) emissions alongside other human forcings (Stott et al. 2010; Bindoff et al. 2013; Jones et al. 2013). Meehl et al. (2004) explored a combination of natural and anthropogenic forcing using a parallel climate model, finding that natural (solar) forcing dominated warming during the early $20^{\text {th }}$ century and anthropogenic forcing (GHG emissions) dominated the late $21^{\text {st }}$-century warming. Egorova et al. (2018) also reported an annual mean global warming rate of $0.3 \mathrm{~K}$ during the early $20^{\text {th }}$ century (1910-1940), with approximately half of this warming attributed to $\mathrm{CO}_{2}, \mathrm{CH}_{4}$, and $\mathrm{N}_{2} \mathrm{O}$ (well-mixed GHGs), and approximately one-third attributed to solar irradiance.

East Asia (EA) is one of the regions most vulnerable to climate change. It is one of the most densely populated regions, containing several major industrial and agricultural centers including high-altitude areas such as the Tibetan Plateau. Thus, the EA region is sensitive to climate change that impacts the global climate as well. Therefore, understanding and assessing climate change across EA is important for estimating and predicting global climate change (Zhou et al. 2004). Increasing SAT trends in EA have been linked to extreme weather events (Xuejie et al. 2002; Li et al. 2018) including heatwaves (Yoon et al. 2018) and intense precipitation (Paik et al. 2020). In response to these challenges, many studies have described the characteristics of SAT changes in EA countries. In China, Tang et al. (2010) reported that SAT increased by $0.78 \pm 0.27^{\circ} \mathrm{C}$ between 1906 and 2005, and Xu et al. (2015) observed a warming of $0.25{ }^{\circ} \mathrm{C} / \mathrm{decade}$ and $0.17{ }^{\circ} \mathrm{C} /$ decade between 1961 and 2005 as a result of GHG emissions and other anthropogenic factors, respectively. The same authors reported that the emission of GHGs is the dominant factor forcing impacting climate change in China. Qian and Qin (2006) analyzed the spatiotemporal characteristics of temperature trends across China using data from 486 meteorological stations, reporting increases of $0.2-0.3^{\circ} \mathrm{C} / \mathrm{decade}$ and $<0.1{ }^{\circ} \mathrm{C} /$ decade in northern and southern China, respectively, between 1960 and 2000 . The same authors report that the greatest increases occurred in winter temperatures $\left(0.5-0.7{ }^{\circ} \mathrm{C} / \mathrm{decade}\right.$ and $0.2-0.3{ }^{\circ} \mathrm{C} /$ decade in northern and southern China, respectively). Mean annual temperature changes in China between 1961 and 2005 were attributed to 
the combined effect of GHG emissions and sulfate aerosol forcing (Xu et al. 2015). Across the Korean Peninsula,

71 extreme heatwave events have also been associated with climate change (Yoon et al. 2020). In North Korea, Om et al.

72 (2019) observed a temperature change of $0.21^{\circ} \mathrm{C} /$ decade from 1918 to 2015 , which is higher than the changes reported

73 for mainland China and the global average. Coastal areas were found to experience lower warming trends than inland regions in North Korea. Similarly, Jung et al. (2002) observed that mean annual SATs in South Korea increased at a rate of $0.23{ }^{\circ} \mathrm{C} /$ decade between 1954 and 1999 , with a higher warming rate during winter. Across the entire Korean Peninsula, Chung and Yoon (2000) reported that the annual mean temperature increased by $0.42{ }^{\circ} \mathrm{C} / \mathrm{decade}$ between 1974 and 1997 in association with GHG emissions, with larger cities experiencing faster warming trends than rural areas and small cities. Wang et al. (2016) also reported a $0.35{ }^{\circ} \mathrm{C} / \mathrm{decade}$ warming in northeast China and a $0.2^{\circ} \mathrm{C} /$ decade warming in Hokkaido, Japan, between 1951 and 2000. They also observed that extreme high- and lowtemperature events were significantly positively correlated between these two regions and the warming recorded in these regions was in the context of global change. Moreover, in Japan, Fujibe (2009) observed that SATs in regions with population densities of over 100 and 3,000 persons $\mathrm{km}^{-2}$ increased at a rate of $0.03-0.05{ }^{\circ} \mathrm{C} / \mathrm{decade}$ and $0.1^{\circ} \mathrm{C} /$ decade, respectively, between 1979 and 2006 . (Allen and Tett 1999; Allen and Stott 2003; Ribes and Terray 2013; Ribes et al. 2013; Wang et al. 2018). Several researchers have used this method to examine temperature increases from regional to global scales, with anthropogenic

87 forcing being identified as the dominant factor in most cases (e.g., Lu et al. 2016; Weller et al. 2016; Wang et al. 2018; Paik and Min 2020). Detection and attribution analyses have been performed using the Coupled Model Intercomparison Project Phase 3 (CMIP3; Santer et al. 2009), Phase 5 (CMIP5; Xu et al. 2015; Yin et al. 2017; Zhang et al. 2019), and the new Phase 6 (CMIP6) model simulations (Paik and Min 2020; Paik et al. 2020) to assess the relative contributions of various external forcings to climate change. Xu et al. (2015) used an optimal detection

92 technique to identify distinct GHG- and anthropogenic (ANT)-associated temperature changes in China between 1961

93 and 2005; Yin et al. (2017) used multimodal CMIP5 simulations for the period 1958-2012 to detect ANT forcing of 94 both extreme cold and warm temperatures in China; and Paik et al. (2020) reported that anthropogenic GHG emissions 95 are the major contributor to extreme precipitation events across a range of climatic settings. As an attribution technique, 96 the optimal fingerprinting method detects both anthropogenic and natural forcings (referred to as 'ALL' forcing) and 97 ANT forcing (Allen and Tett 1999, Ribes and Terray 2013). Applying this approach to China, Wang et al. (2018) 
showed that warming in western China can be attributed to anthropogenic forcing, and also projected the future warming trends of this region. Yin et al. (2017) detected human influences on the intensity of extreme temperature changes in China, as well as at regional scales in eastern and western China, from 1958-2012. Lu et al. (2016) found anthropogenic influences on the frequency of daily temperature extremes in China using detection and attribution analysis. Furthermore, model-simulated responses were consistent with observations of the daytime extremes. Many researchers have described anthropogenic influences on changes in temperature and precipitation over China (Song et al. 2015; Burke et al. 2016; Sun et al. 2016; Li et al. 2017; Ma et al. 2017; Li et al. 2018a; Qian et al. 2018; Zeng et al. 2019).

Most of the studies mentioned above focused on climate change in China and few studies have focused on Korea or Japan. Furthermore, most studies have considered the period 1950-2010 and employed CMIP3 and CMIP5 model simulations. To the best of our knowledge, CMIP6 datasets have not yet been used to examine EA climate trends during the historical period from 1850 to 2014 nor have future projections (2015-2100) been provided at this scale. There are also no detection and attribution studies of climate change across the whole of EA. To address this gap, here we focus on SAT changes in EA between the second half of the $19^{\text {th }}$ century and the $21^{\text {st }}$ century based on the new state-of-the-art multi-model CMIP6 simulations. This allows us to describe the contributions of external and natural forcings on climate change in this region. Based on our analysis, we also describe the relative contributions of each forcing in each EA country as well as across the EA as a whole. The main focus of the study is to examine the effect of human-induced/anthropogenic forcings on climate change over EA using CMIP6 simulations. We also provide future projections of each EA country and the entire EA region based on three different scenarios.

The rest of the paper is structured as follows. Section 2 describes the data and methodology and Section 3 provides a discussion of our results including observed and simulated temperature trends in response to the different forcing factors, the detection and attribution results, and the observation-constrained future projections. Finally, a summary of our findings and our conclusions are presented in Section 4.

\section{Data and methodology}

We used the CRU time series version 4.03 (resolution $=0.5^{\circ} \times 0.5^{\circ}$ ) and HadCRUT4 (resolution $=5^{\circ} \times 5^{\circ}$ ) observational datasets for the period 1901-2018 and 1850-2019, respectively; the HadCRUT4 dataset (available at https://crudata.uea.ac.uk/cru/data/temperature/) was primarily used to cover the period not considered by the CRU 
dataset (1850-1900). The CRU data are derived from the interpolation of monthly climate anomalies of worldwide weather station observations (Peng et al. 2018; Harris et al. 2020; Drumond et al. 2021) and are available at https://crudata.uea.ac.uk/cru/data/hrg/. These CRU data have been used by many researchers studying long-term temperature and precipitation changes over the EA region ( $\mathrm{Li}$ et al. 2018b; Peng et al. 2018; Chen et al. 2019; Harris et al. 2020) and they correlate well with ground station datasets. We separated the land and ocean data, and the former was used for this study. The state-of-the-art global multimodal simulations of CMIP6 (Eyring et al. 2016), supported by the World Climate Research Program, were used to estimate the influence of different external forcings and is available at https://esgf-node.llnl.gov/projects/cmip6/. Some of the CMIP6 models are more biased when compared to observational datasets (Almazroui et al. 2020, Almazroui et al. 2021). Therefore, we used multimodal ensemble mean values to mitigate any bias and obtain the most accurate values possible. The various CMIP6 models (Table 1) were re-gridded using bilinear interpolation to achieve a uniform resolution of $1^{\circ} \times 1^{\circ}$. The $20^{\text {th }}$ century historical and $21^{\text {st }}$ century future shared socioeconomic pathway (SSP) scenarios were used to define historical and future temperature trends, respectively. The CMIP6 simulations of historical (ALL), hist-aer (AER), hist-nat (NAT), histGHG (GHG), hist-sol (SOL), and land-hist (LU), which were represent all, anthropogenic aerosol only, natural only, GHG only, solar irradiance only, and land use only forcings, respectively; and were used to define their influence on the temperature trends. Robust regression technique was used for the trends estimation, which detect the effects of outliers and end points (Street et al. 1988). The low SSP1-2.6 and SSP2-4.5 scenarios and high SSP5-8.5 scenarios were used for the future projections (2015-2100). Initially, the monthly anomalies of the historical (considered land data and discarded ocean data) datasets (ALL, AER, NAT, GHG, SOL, and LU) and future scenarios (SSP1-2.6, SSP2-4.5, and SSP5-8.5) were collected from CMIP6. The simulations driven with ALL from 21 models, had 91 runs. The simulations driven by the other forcings of AER, NAT, GHG, LU, and SOL included 10 (46), 10 (48), 11 (46), 8 (13), and 4 (22) models (runs), respectively. Similarly, the future projections driven by SSP1-2.6, SSP2-4.5, and SSP5-8.5 included 17 (54), 18 (67), and 17 (59) models (runs), respectively (see Table 1). The $1^{\circ} \times 1^{\circ}$ gridded data were averaged for their respective models. Then, if the grids did not contain any observations, the corresponding grids of the models were masked out to match the observations. Initially, we averaged all the ensemble members (runs) for each model, and the multi-model ensemble (MME) mean was estimated as the equally weighted arithmetic average of all the individual model ensemble means. Monthly anomalies were computed for each grid $\left(1^{\circ} \times 1^{\circ}\right)$ and then yearly and decadal anomalies were evaluated. Finally, regional mean series were estimated based on the available grid values, 
weighted by the cosine of the latitude at the center of each grid box area, for each EA country, as well as the entire EA region.

Regularized optimal fingerprinting (ROF) was used for detection and attribution analysis based on the different forcings (Ribes et al. 2013). This approach can assess the contribution of external forcings based on the scaling factors in a linear regression model (Allen and Tett 1999; Ribes et al. 2013). ROF is similar to classical optimal fingerprinting except that a regularized covariance matrix is used for the optimization and estimation of the nulldistribution used for the residual consistency test. ROF is based on the space-time evolution of SAT trends and is more accurate than the classical optimal detection method (Ribes et al. 2013; Zhang et al. 2019), overcoming the limitation of empirical orthogonal function truncations. This method generates a full-rank measure of the covariance matrix of internal variability, which does not require empirical orthogonal function truncation (Ribes et al 2013; Tokarska et al. 2019). Furthermore, it assumes that the climate response and noise signals are linearly additive, which means that the observed changes are the sum of climate response (externally forced change) and internally generated noise (Bindoff et al. 2013; Zhang et al. 2019). In ROF, the observations (Y) are regressed onto the MME mean signal patterns (X) using total least squares method (Ribes et al. 2013), such that $Y=(X-v) \beta+\varepsilon$. Here, $\beta$ represents an unknown regression coefficient or scaling factor. All traces of internal variability are not removed from the MME mean and, therefore, the remaining internal variability effects in $\mathrm{X}$ are represented as $\mathrm{v}$. $\varepsilon$ is the noise owing to internal variability (the regression residual). The internal variability $(\varepsilon)$ was estimated from the model simulations. We used pre-industrial control (CTL) simulations of 21 models (see Table 1) to estimate internal climate variability and increase the independent noise data; this reduces the sampling uncertainty in covariance estimations (Ribes et al. 2013). These CTL simulations were divided into 283 non-overlapping segments that were each 110 years long (the segment length was equal to the 1905-2014 period used for the detection analysis). The CTL simulations were divided into two sets of equal size, one was used for optimization and to derive the best estimates, and the other was used to calculate the 5-95\% confidence intervals of the scaling factors and also to carry out the residual consistency test (Allen and Tett 1999; Ribes et al. 2013). The residual consistency test uses a nonparametric estimation of the null distribution through Monte-Carlo simulations to determine whether the noise estimate $(\varepsilon)$ is consistent with the simulated internal variability (Ribes and Terray 2013; Tokarska et al. 2019). The influence of the different forcings were detected based on $\beta$. A $90 \%$ confidence interval of $\beta$ greater than zero implies that a corresponding influence of external forcing has been detected. If the $90 \%$ range of $\beta$ is above zero and it includes unity, this indicates that the observed change is 
consistent with the model simulations. If the $90 \%$ interval of $\beta$ is greater (less) than unity, this implies that the observed changes are underestimated (overestimated) by the model simulations. For further details regarding the ROF method, refer to Ribes et al. (2013) and Ribes and Terray (2013).

For detection and attribution, we used the MME means of the available simulations for ALL, GHG, ANT, and NAT, which largely smoothed the uncorrelated internal variations (Zhang et al. 2019). ANT was estimated by subtracting NAT from ALL (ANT = ALL - NAT). We conducted one-signal, two-signal, and three-signal analyses over the last hundred years (1905-2014) for each EA country and EA overall. Detection and attribution are most effective at small data dimensions, allowing better estimation of climate response and, thus, are usually conducted within shorter dimensions (Xu et al. 2015). Therefore, we converted the annual data sets into non-overlapping tenyear means for the 1905-2014 period, which produced 11 data values $(1905-1914,1915-1924,1925-1934, \ldots$ and 2005-2014). The use of 10-year temporal means reduced the time dimension, as well as the variability of the observations and noise in the climate signals (Wang et al. 2018; Zhang et al. 2019). In the one-signal analysis (Eq. 1), the observations were regressed onto MME mean responses of ALL and ANT fingerprints separately to detect their 194 relative influence on the observed change. In the two-signal analysis (Eq. 2), the observations were regressed simultaneously onto the MME mean responses of ANT and NAT fingerprints to determine their separate contributions.

196 In the three-signal analysis (Eq. 4), the observations were regressed onto the MME mean response patterns from the 197 GHG, ANTnoGHG (i.e., ANT - GHG), and NAT simulations simultaneously to clearly detect and isolate the GHG 198 forcing effect.

$199 \quad \mathrm{Y}_{\mathrm{OBS}}=\beta_{\mathrm{M}} \mathrm{X}_{\mathrm{M}}+\varepsilon$

$200 \quad \mathrm{Y}_{\mathrm{OBS}}=\beta_{\mathrm{ANT}} \mathrm{X}_{\mathrm{ANT}}+\beta_{\mathrm{NAT}} \mathrm{X}_{\mathrm{NAT}}+\varepsilon$

$201 \mathrm{X}_{\mathrm{ALL}}=\mathrm{X}_{\mathrm{ANT}}+\mathrm{X}_{\mathrm{NAT}}$

$203 \mathrm{X}_{\mathrm{ALL}}=\mathrm{X}_{G H G}+\mathrm{X}_{\mathrm{ANTnOGHG}}+\mathrm{X}_{\mathrm{NAT}}$

where $\mathrm{Y}_{\mathrm{OBS}}$ represents the observations; $\mathrm{X}$ indicates the model simulations; $\mathrm{M}$ is the fingerprints of ALL, GHG, ANT, ANTnoGHG, and NAT; $\beta$ is the unknown regression coefficient or scaling factor; $\varepsilon$ is the regression residual term, 
which represents the noise due to internal variability; $\mathrm{X}_{\mathrm{ALL}}, \mathrm{X}_{\mathrm{GHG}}, \mathrm{X}_{\mathrm{ANT}}, \mathrm{X}_{\mathrm{ANTnoGHG}}$, and $\mathrm{X}_{\mathrm{NAT}}$ are the model simulation responses to the ALL, GHG, ANT, ANTnoGHG, and NAT forcings, respectively; and $\beta_{\mathrm{GHG}}, \beta_{\mathrm{ANT}}, \beta_{\mathrm{ANTnoGHG}}$, and $\beta_{\mathrm{NAT}}$ are scaling factors corresponding to the GHG, ANT, ANTnoGHG, and NAT forcings, respectively.

\section{Results and discussion}

Figures 1a and 1b show the annual mean temperatures from 1901 to 2014 estimated from CRU and CMIP6 (ALL forcings), respectively. The mean temperature varied between $-15{ }^{\circ} \mathrm{C}$ and $30{ }^{\circ} \mathrm{C}$ throughout EA. Southeast China showed the highest mean temperature (approximately $25^{\circ} \mathrm{C}$ ), while Tibet and northwest Mongolia showed the lowest $\left(<0{ }^{\circ} \mathrm{C}\right)$. In Korea and Japan, the mean temperature varied from 4 to $16{ }^{\circ} \mathrm{C}$. The performance of the CMIP6 model simulations was validated in comparison with the CRU observations. The bias (CMIP6 - CRU) across EA and in all EA countries is shown in Figures 1c and 1d. In Figure 1d, the $25 \%$ and $75 \%$ quartiles indicate a bias of $<1.8{ }^{\circ} \mathrm{C}$.

217 Overall, the mean bias for EA was $\leq 0.5^{\circ} \mathrm{C}$, indicating that the performance of the CMIP6 simulations was satisfactory.

218 Figures 1a and $1 \mathrm{~b}$ also show that the mean temperature values of CRU and CMIP6 outputs are consistent. The Student's $t$ test also showed no significant differences between the observations and model estimations at the selected time period (significance level $<0.05$ ). Further, we compared the trends of the simulations and observations (see Figure 3 and the following paragraphs), which showed good agreement.

We also evaluated the spatial distributions of the annual mean SAT MME mean response trends to the different forcings for the period 1850-2014. Figures 2a-e correspond to the temperature trends associated with the ALL, AER, NAT, GHG, and SOL forcings. The trends are estimated based on robust regression analysis. The LU datasets were only available for very few models and did not cover all the EA regions (Table 1) owing to their low spatial resolutions. Therefore, the distributions for LU are not presented here. The lowest increases in temperature owing to ALL and GHG occurred in southeast China, while the highest increases were observed in Tibet and southern

228 Mongolia. As the third industrial revolution began in 1969, we also estimated the temperature changes over the last 40 years (1971-2014; Table 2). The SAT response to ALL forcings clearly shows a positive trend throughout EA during the study period, with an increase of approximately $0.031{ }^{\circ} \mathrm{C} /$ decade between 1850 and 2014 (Period $\left.1=\mathrm{P} 1\right)$ and $0.255{ }^{\circ} \mathrm{C} / \mathrm{decade}$ between 1971 and 2014 (P2). Overall, Mongolia showed the highest rate of increase at 
in P2. AER showed a negative and the lowest temperature trend in all the EA countries (Figure $2 \mathrm{~b}$ and Table 2). Thus, it is determined that AER cools SAT and slows the warming rate. Across EA, the overall AER cooling trend was $-0.076{ }^{\circ} \mathrm{C} /$ decade during $\mathrm{P} 1$ and $-0.035^{\circ} \mathrm{C} /$ decade in $\mathrm{P} 2$. Interestingly, in $\mathrm{P} 2$, Mongolia showed a positive/increasing trend in association with the highest degree of warming observed in this region. Figure $2 \mathrm{c}$ shows that the SAT values were less influenced by NAT forcing, and Table 2 shows slightly negative NAT values for P1 in all the EA countries compared to positive trends during P2. Consequently, SATs in EA remained relatively stable during P1 $\left(-0.003{ }^{\circ} \mathrm{C} /\right.$ decade $)$ in $\mathrm{P} 1$ and $\mathrm{P} 2\left(0.019^{\circ} \mathrm{C} /\right.$ decade $)$ in response to NAT forcing. The increasing trends during $\mathrm{P} 2$ can be attributed to the third industrial revolution. The third industrial revolution (1969-2000) was most prominent in the region of China, Japan, and Korea, where significant development took place (for example, new industries and technologies were established) (Janicke and Jacob 2013; Lixing 2013; Wen 2016). Thus, the surface temperature increased significantly over EA and the global climate was also affected (figure not shown). Tett et al. (2002) also found that temperatures increased by $0.1 \mathrm{~K}$ from $1900-1960$ and then subsequently (1960-1997) increased by $0.5 \mathrm{~K}$, owing to anthropogenic effects over the global scale. GHG forcing produced the strongest warmest trend among all the forcings (Figure 2d) corresponding to $0.082{ }^{\circ} \mathrm{C} /$ decade across all of EA during P1 and $0.268{ }^{\circ} \mathrm{C} /$ decade during P2. Mongolia, China, Korea, and Japan showed higher warming rates as a result of GHG forcing during P2 than during P1 (Table 2). A significant increase in GHG forcing effects can be seen for P2, again indicating the impact of industrialization during this period. The SOL forcing effects (Figure 2e) show mostly stable trends during P1 and P2, with values of 0.005 and $0.008{ }^{\circ} \mathrm{C} / \mathrm{dec}$ ade for the entire EA region, respectively. The average temperature trends in response to LU forcing are shown in Table 2 for each EA region, which associated with warming trends. Across all of EA, LU increased SATs by by 0.084 and $0.239^{\circ} \mathrm{C} /$ decade during P1 and P2, respectively. Over EA, LU changes caused significant temperature increases owing to a reduction of plant transpiration after deforestation and desertification; i.e., changes from forest to shrubland or cropland lead to increases in sensible heat flux and drying of the soil (Gao et al. 2003). LU changes can also reduce precipitation (Dale 1997). These trends further indicate an enhanced warming rate after industrialization (P2).

The MME mean responses of ALL, GHG, LU, AER, NAT, and SOL of each forcing was averaged for each

258 EA country as well as for the whole of EA. The annual temperature anomalies for each forcing were calculated relative to the 1850-2019 period; anomalies were also estimated for 1850-2014, which was the period for which ALL forcing simulations were available. Figure 3 shows the temperature anomalies of ALL forcings as well as ground observations, 

trends associated with ALL forcings were consistent with the observed trends. The SATs in the HadCRUT4 and ALL datasets were mostly stable between 1850 and 1900, after which SAT dropped. This may have been caused by the cooling effect of AER. From 1901 to 1970, the observations (CRU and HadCRUT4) and the ALL data anomalies show slow increasing SAT trends. However, from 1970 to 2014/2019, SAT increased rapidly owing to the third industrial revolution. Across all of EA, SAT had increased by $1.5^{\circ} \mathrm{C}$ by 2019 , with trends in each country being broadly similar. Specifically, under the ALL forcings, all the East Asian countries experienced smaller increments of change between 1900 and 1969 compared to a higher rate of increase between 1970 and 2014. By 2019, the SATs in China and Japan had increased by $\geq 1{ }^{\circ} \mathrm{C}$, while in Korea and Mongolia, the increase had reached $\geq 1.5^{\circ} \mathrm{C}$. The SAT anomaly response to GHG forcing is shown in Figure 4 for the period 1850-2019, with observational and simulated SAT datasets showing a similar increasing trend. A slow increase in GHG forcing is observed until 1969, after which SATs begin to increase very rapidly. Indeed, GHG forcing has been the dominant contributor to the observed SAT warming in each country as well as across the whole of EA. For example, GHG forcing increased SATs by approximately $1.9^{\circ} \mathrm{C}$ throughout EA and China by 2019 , with even higher degrees of warming $\left(\geq 2{ }^{\circ} \mathrm{C}\right)$ in Mongolia and Korea. In Japan the equivalent temperature increase was $\leq 2{ }^{\circ} \mathrm{C}$. In response to LU forcing, SAT warming rates closely match the CRU/HadCRUT4 observations (Figure S1 in Supplementary material). The temperature trend response to AER forcing was negative throughout EA and in each country (Figure 5), indicating that the cooling effect of AER forcing partially counteracts the warming caused by other forcings. The SAT changes in response to the NAT and SOL forcings are shown in Figures 6 and S2 (Supplementary material), respectively, which remained broadly stable in all the EA regions indicating minimal forcing effects.

Table 3 shows the correlations between the SAT trends of the observed data (CRU) and the response to different forcings based on the CMIP6 historical models. The SAT response to LU is strongly correlated with the CRU SAT data, and ALL and GHG also show positive correlations. In contrast, AER is negatively correlated with the CRU data, and NAT and SOL show very weak/no correlation. These correlations clearly demonstrate the direction (i.e., warming or cooling) and relative strength of the contributions of the different forcing factors to SAT changes over the entire study period. Specifically, ALL, GHG, and LU forcings are associated with SAT increases; AER forcing produced a cooling effect; and NAT and SOL forcings had very weak or no impact on the warming rate. 
We conducted detection and attribution analysis based on the ROF method for the annual mean temperature in EA over the last 110 years (1905-2014). The scaling factors, with 90\% confidence intervals, of the one-, two-, and three-signal analyses are presented in Figure 7. One-signal analyses were performed on the individual forcings of ALL (best estimate 1.16 with $90 \%$ confidence interval of 0.85 to 1.47) and ANT (best estimate 1.21 with $90 \%$ confidence interval of 0.9 to 1.56), as shown in Figure 7a. The 90\% confidence intervals of ALL, and ANT are above zero, indicating that these forcings are robustly detected in EA. The best estimate of ALL is greater than unity indicates the observed changes were underestimated by MME mean in response to ALL. Furthermore, the best estimates of ALL, and ANT are close to unity, indicating detection results pass the residual consistency test, which representing the good agreement between model simulations and observed changes. The two-signal analyses were performed on the ANT (best estimate 1.24 with $90 \%$ confidence interval of 0.91 to 1.57 ) and NAT (best estimate 0.16 with $90 \%$ confidence interval of -1.32 to 1.66) forcings, the scaling factors of which are shown in Figure $7 \mathrm{~b}$ with $90 \%$ confidence intervals. The best estimates of ANT (1.24) and NAT (0.16) suggests that the effect of ANT can be separated from NAT. Further, ANT is robustly detected in EA, with a $90 \%$ confidence interval above zero; the best estimate is close to unity and is also comparable with ANT in the one-signal analysis, implying the robustness of anthropogenic influence on the observed temperature changes. In comparison, the lower bound of the NAT forcing is below zero, indicating that this forcing is undetected in EA. Therefore, only anthropogenic forcing can explain the observed annual mean temperature changes in EA from 1905 to 2014.

We conducted the three-signal analyses using GHG (best estimate 0.89 with $90 \%$ confidence interval of 0.48 to 1.29 ), ANTnoGHG (best estimate 0.77 with $90 \%$ confidence interval of -0.54 to 2.1 ), and NAT (best estimate 0.68 with $90 \%$ confidence interval of -0.82 to 2.21 ) to determine the major contributors among the anthropogenic forcings or other factors causing changes in the observations. This analysis also explored the influence of GHG forcing on SAT variations. Figure 7c shows the scaling factors for GHG, ANTnoGHG, and NAT. GHG is robustly detected in EA, 311 with a 90\% confidence interval above zero and a best estimate close to unity, which implies good agreement with the 312 observations. In contrast, the lower bounds of the ANTnoGHG and NAT forcing include zero indicate that these are not detected in EA. Therefore, GHG forcing can be separated from ANTnoGHG and NAT forcing, and is considered 314 the dominant anthropogenic factor forcing for the observed temperature changes in the study region. 
The one-signal analysis shown in Figure 7a demonstrates that the best estimate of ALL forcings is 1.16 (above 1), indicating an underestimation of the CMIP6 historical simulations. This historical underestimation could continue in future projections, requiring appropriate adjustment/correction to ensure the accurate estimation of future scenarios. Therefore, the MME mean future projections under the low SSP1-2.6 and SSP2-4.5, and high SSP5-8.5, scenarios were multiplied by the best estimate of the ALL forcing scaling factor obtained in the one-signal analysis. Figure 8a shows the resulting historic (1850-2014) and future scenarios (2015-2100) for EA. These observationconstrained future projections show higher warming rates than the raw simulations. The adjusted/best estimate of the future projections of SSP1-2.6, SSP2-4.5, and SSP5-8.5 show temperature increases of $2.32{ }^{\circ} \mathrm{C}(90 \%$ confidence interval: $\left.1.80-3.15{ }^{\circ} \mathrm{C}\right), 2.46{ }^{\circ} \mathrm{C}\left(90 \%\right.$ confidence interval: $\left.1.78-3.16{ }^{\circ} \mathrm{C}\right)$, and $3.12{ }^{\circ} \mathrm{C}(90 \%$ confidence interval: 2.55-3.90 ${ }^{\circ} \mathrm{C}$ ), respectively by 2050 compared to $1.92{ }^{\circ} \mathrm{C}, 2.12{ }^{\circ} \mathrm{C}$, and $2.68{ }^{\circ} \mathrm{C}$ based on the unadjusted simulations, respectively; by 2070 , the best estimate temperature increases under SSP1-2.6, SSP2-4.5, and SSP5-8.5 are $2.64{ }^{\circ} \mathrm{C}$ (90\% confidence interval: $1.97-3.29{ }^{\circ} \mathrm{C}$ ), $3.10{ }^{\circ} \mathrm{C}$ (90\% confidence interval: $2.34-3.89{ }^{\circ} \mathrm{C}$ ), and $4.61{ }^{\circ} \mathrm{C}(90 \%$ confidence interval: $4.17-5.28{ }^{\circ} \mathrm{C}$ ), respectively, compared to $2.28{ }^{\circ} \mathrm{C}, 2.64{ }^{\circ} \mathrm{C}$, and $3.95{ }^{\circ} \mathrm{C}$ based on the original simulations; and by 2100 , the best estimates under the same three scenarios are $2.49{ }^{\circ} \mathrm{C}(90 \%$ confidence interval: 1.84-3.12 $\left.{ }^{\circ} \mathrm{C}\right), 3.66{ }^{\circ} \mathrm{C}\left(90 \%\right.$ confidence interval: $\left.3.07-4.27{ }^{\circ} \mathrm{C}\right)$, and $7.22{ }^{\circ} \mathrm{C}\left(90 \%\right.$ confidence interval: $\left.6.79-8.15^{\circ} \mathrm{C}\right)$ compared to $2.17{ }^{\circ} \mathrm{C}, 3.15^{\circ} \mathrm{C}$, and $6.19^{\circ} \mathrm{C}$ based on the original simulations, respectively. We also estimated the best values for the ALL forcing scaling factors for each EA country and generated projections for each EA country. The best estimates for the ALL forcing scaling factors, with 90\% confidence intervals, for each EA country are shown in Table 4. The country-scale future projections under each of the scenarios were adjusted based on their respective ALL forcing best estimates, as shown in Figures 8b-e. The best estimates of the future projections of SSP1-2.6, SSP2-4.5, and SSP5-8.5, with 90\% confidence intervals, for each EA country in 2050, 2070, and 2100 are shown in Table 5.

337 The resulting observation-constrained future projections in all the EA countries show higher warming rates relative to the raw simulation data, and warming is projected to increase over time.

\section{Summary and conclusions}

This study describes long-term SAT changes in EA using the new state-of-the-art CMIP6 multi-model simulations. These model simulations were validated in comparison with CRU/HadCRUT4 observational 
measurements. The SAT variation responses to various external and natural forcings (ALL, AER, NAT, GHG, SOL, and LU) were examined between 1850 and 2014/2019. Throughout EA, southeast China has experienced the highest 344 mean temperatures (approximately $25^{\circ} \mathrm{C}$ ) compared to the lowest on the Tibetan Plateau (approximately $-12{ }^{\circ} \mathrm{C}$ ). SATs during the study period were increased due to GHG and LU forcings and decreased due to the AER forcing. In contrast, NAT and SOL had little impact on SAT changes. GHG forcing was the dominant factor in the observed temperature increase. Overall, the SAT in EA increased by $0.082^{\circ} \mathrm{C} /$ decade in response to the GHG forcing, compared to $0.031{ }^{\circ} \mathrm{C} /$ decade under ALL forcings from 1850-2014. After the third industrial revolution, SATs increased very rapidly, by 0.268 and $0.255{ }^{\circ} \mathrm{C} /$ decade in response to the GHG and ALL forcings, respectively, between 1970 and 2014 (Tett et al. 2002). By 2019, the GHG forcing had increased the SAT across the EA by approximately $1.9{ }^{\circ} \mathrm{C}$, and all countries in EA had also experienced increasing SAT trends as a result of anthropogenic forcings (GHG, and LU).

Overall, Mongolia experienced faster rates of temperature rise than other EA countries; however, throughout EA, the highest and lowest amounts of warming occurred in Tibet and southeast China, respectively. The strongest cooling response to AER forcing occurred in southeast China, while across EA, the overall cooling rate associated with AER forcing was approximately $-0.076{ }^{\circ} \mathrm{C} /$ decade between 1850 and 2014. Interestingly, in Mongolia, AER showed a warming rather than cooling influence during the 1971-2014 period, which might partially explain the high degree of warming in this region. Across EA, LU increased the temperature by $0.084{ }^{\circ} \mathrm{C}$, between 1850 and 2014 , while NAT and SOL forcings had a minimal effect overall. The changes in LU increased the temperature owing to reduced vegetation cover and desertification. Based on these observations, anthropogenic forcing has significantly influenced the climate of EA, associated with distinct warming trends. Furthermore, we present future SAT projections up to 2100 based on the low SSP1-2.5 and SSP2-4.5, and high SSP5-8.5, scenarios.

We applied the ROF detection and attribution technique to CMIP6 simulations to describe climate change in EA resulting from anthropogenic influences. The ALL and ANT forcings were robustly detected from the one-signal analyses for the period 1905-2014; in the two-signal analysis, ANT and NAT influences could be separated, and the ANT forcing was clearly detected as a factor including the increase in SATs; and in the three-signal analysis, GHG forcing was separated from ANTnoGHG and NAT forcings and was strongly detected, indicating that GHG forcing was the dominant factor driving climate change in EA. Finally, we generated adjusted/corrected future warming trends by multiplying the raw simulation data with the ALL forcing best estimates, which produced higher projected 
temperature values under the SSP1-2.5, SSP2-4.5, and SSP5-8.5 scenarios. Overall, we conclude that the climate

370 (SAT) changes observed in EA are the result of anthropogenic forcings, primarily GHG and LU. This implies that

371 efforts to mitigate future climate change in this region should focus on these anthropogenic forcing factors.

\section{$372 \quad$ Funding}

373 This work was supported by the Korea Institute of Civil Engineering and Building Technology Strategic Research

374 Project (Establishment of 3D Fine Dust Information Based on AI Image Analysis).

\section{Conflicts of interest}

376 The authors declare no conflict of interest.

\section{Availability of data and material}

378 The datasets were used in the present study are HadCRUT4 available at https://crudata.uea.ac.uk/cru/data/temperature/;

379 CRU available at https://crudata.uea.ac.uk/cru/data/hrg/; and CMIP6 available at https://esgf380 node.llnl.gov/projects/cmip6/.

381 Code availability

382 The code for regularized optimal fingerprinting method used for detection and attribution analysis is available at http://www.umr-cnrm.fr/spip.php?article23\&lang=en.

\section{Authors' contributions}

385 Shaik Allabakash performed data analyses and conceptualization and wrote the first manuscript draft. Sanghun Lim 386 provided helpful discussions on the analyses of data, conceptualization, methodology, and review and edited the 387 manuscript.

\section{Acknowledgments}

389 This work was supported by the Korea Institute of Civil Engineering and Building Technology Strategic Research 390 Project (Establishment of 3D Fine Dust Information Based on AI Image Analysis). We acknowledge the World 391 Climate Research Program for making the CMIP6 dataset available for global- and regional-scale climate research. 392 The authors would like to thank the National Climate Center, Research, for providing the CRU dataset. 


\section{References}

395 Allen MR, Stott PA (2003) Estimating signal amplitudes in optimal fingerprinting, Part I: Theory. Clim Dynam 21:477-491.

Allen MR, Tett SF (1999) Checking for model consistency in optimal fingerprinting. Clim Dynam 15:419-434.

Almazroui M, Islam MN, Saeed F., Saeed S, Ismail M, Ehsan MA, Diallo I, O’Brien E, Ashfaq M, Martínez-Castro the Caribbean in CMIP6 GCMs. Earth Syst Environ 5:1-24. South Asian countries in CMIP6. Earth Syst Environ 4:297-320.

Bindoff NL, Stott PA, AchutaRao KM, Allen MR, Gillett N, Gutzler D, Hansingo K, Hegerl G, Hu Y, Jain S, Mokhov

404 II (2013) Detection and attribution of climate change: from global to regional. The Intergovernmental Panel on Climate 405 Change (IPCC).

406 Burke C, Stott P, Sun Y, Ciavarella A (2016) Attribution of extreme rainfall in Southeast China during May 2015. In:

407 Explaining Extreme Events of 2015 from a Climate Perspective. Bull Am Meteorol Soc 97:S92-S96.

408 Chen L, Chen X, Cheng L, Zhou P, Liu Z (2019) Compound hot droughts over China: identification, risk patterns and 409 variations. Atmos Res 227:210-219.

410 Chung YS, Yoon MB (2000) Interpretation of recent temperature and precipitation trends observed in Korea. Theor 411 Appl Climatol 67:171-180.

412 Dale VH (1997) The relationship between land-use change and climate change. Ecol Appl 7:753-769.

413 Drumond A, Stojanovic M, Nieto R, Gimeno L, Liberato ML, Pauliquevis T, Oliveira M, Ambrizzi T (2021) Dry and 414 wet climate periods over eastern South America: identification and characterization through the SPEI 415 index. Atmosphere, 12:155.

416 Egorova T, Rozanov E, Arsenovic P, Peter T, Schmutz W (2018) Contributions of natural and anthropogenic forcing 417 agents to the early 20th century warming. Front Earth Sci 6:206. 
418 Eyring V, Bony S, Meehl GA, Senior CA, Stevens B, Stouffer RJ, Taylor KE (2016) Overview of the Coupled Model

419 Intercomparison Project Phase 6 (CMIP6) experimental design and organization. Geosci Model Dev 9:1937-1958.

420 Fujibe F (2009) Detection of urban warming in recent temperature trends in Japan. Int J Climatol 29:1811-1822.

421 Gao XJ, Luo Y, Lin WT, Zhao ZC, Giorgi F (2003) Simulation of effects of land use change on climate in China by

422 a regional climate model. Adv Atmos Sci 20:583-592.

425 Harris I, Osborn TJ, Jones P, Lister D (2020) Version 4 of the CRU TS monthly high-resolution gridded multivariate 426 climate dataset. Sci Data 7:1-18.

427 Janicke M, Jacob K (2013) A third industrial revolution. In: Siebenhüner B, Arnold M, Eisenack K, Jacob KH (eds)

428 Long-term governance for social-ecological change. Routledge, New York, pp 47-71.

429 Jones GS, Stott PA, Christidis N (2013) Attribution of observed historical near-surface temperature variations to 430 anthropogenic and natural causes using CMIP5 simulations. J Geophys Res: Atmos 118:4001-4024.

431 Jung HS, Choi Y, Oh JH, Lim GH (2002) Recent trends in temperature and precipitation over South Korea. Int J 432 Climatol 22:1327-1337.

433 Li H, Chen H, Wang H (2017) Effects of anthropogenic activity emerging as intensified extreme precipitation over 434 China. J Geophys Res: Atmos 122:6899-6914.

435 Li K, Liao H, Cai W, Yang Y (2018a) Attribution of anthropogenic influence on atmospheric patterns conducive to 436 recent most severe haze over eastern China. Geophysical Research Letters, 45:2072-2081.

437 Li D, Zhou T, Zou L, Zhang W, Zhang L (2018b) Extreme high-temperature events over East Asia in $1.5^{\circ} \mathrm{C}$ and $2{ }^{\circ} \mathrm{C}$ 438 warmer futures: analysis of NCAR CESM low-warming experiments. Geophys Res Lett 45:1541-1550.

439 Lixing Z (2013) The third industrial revolution and development strategies of China. In: International affairs forum, 440 Vol 4. Routledge, New York, pp. 79-82.

441 Lu C, Sun Y, Wan H, Zhang X, Yin H (2016) Anthropogenic influence on the frequency of extreme temperatures in 442 China. Geophys Res Lett 43:6511-6518. 

anthropogenic shift toward heavy precipitation over eastern China. J Clim 30:1381-1396. and anthropogenic forcings in twentieth-century climate. J Clim 17:3721-3727.

Om KC, Ren G, Jong SI, Li S, Kang-Chol O, Ryang CH, Zhang P (2019) Long-term change in surface air temperature over DPR Korea, 1918-2015. Theor Appl Climatol 138: 363-372. decline using the CMIP6 multimodel ensemble. J Clim 33:9261-9269. contribution to the observed intensification of extreme precipitation. Geophys Res Lett 47:e2019GL086875. 1901 to 2100. Int J Climatol 38:2250-2264. 16. A, Kossin JP, Schreck CJ III, and Stott PA (eds) Explaining extreme events of 2016 from a climate perspective. Bull Am Meteorol Soc 99:S118-S122.

Ribes A, Planton S, Terray L (2013) Application of regularised optimal fingerprinting to attribution. Part I: method, 463 properties and idealised analysis. Clim Dynam 41:2817-2836.

464 Ribes A, Terray L (2013) Application of regularised optimal fingerprinting to attribution. Part II: application to global near-surface temperature. Clim Dynam 41:2837-2853.

467 W, Gillett NP (2009) Incorporating model quality information in climate change detection and attribution studies. Proc $468 \quad$ Natl Acad Sci 106:14778-14783. 

China. Bull Am Meteorol Soc 96:S111- S114.

471 Stocker TF, Qin D, Plattner GK, Tignor MM, Allen SK, Boschung J, Nauels A, Xia Y, Bex V, Midgley PM (2014)

472 Climate Change 2013: the physical science basis. Contribution of working group I to the fifth assessment report of the

473 IPCC, the intergovernmental panel on climate change. Cambridge University Press, Cambridge and New York.

474 Stott PA, Gillett NP, Hegerl GC, Karoly DJ, Stone DA, Zhang X, Zwiers F (2010) Detection and attribution of climate 475 change: a regional perspective. WIRES: Clim Change 1:192-211.

476 Street JO, Carroll RJ, Ruppert D (1988) A note on computing robust regression estimates via iteratively reweighted 477 least squares. Am Stat 42:152-154.

478 Sun Y, Song L, Yin H, Zhang X, Stott P, Zhou B, Hu T (2016) Human influence on the 2015 extreme high temperature 479 events in Western China. Bull Am Meteorol Soc 97:S102-S106.

480 Tang G, Ding Y, Wang S, Ren G, Liu H, Zhang L (2010) Comparative analysis of China surface air temperature series 481 for the past 100 years. Adv Clim Change Res 1:11-19.

482 Tett SF, Jones GS, Stott PA, Hill DC, Mitchell JF, Allen MR, Ingram WJ, Johns TC, Johnson CE, Jones A, Roberts 483 DL (2002) Estimation of natural and anthropogenic contributions to twentieth century temperature change. J Geophys 484 Res: Atmos 107:ACL-10.

485 Tokarska KB, Hegerl GC, Schurer AP, Ribes A, Fasullo JT (2019) Quantifying human contributions to past and future 486 ocean warming and thermosteric sea level rise. Environ Res Lett 14:074020.

487 Wang L, Wu Z, Wang F, Du H, Zong S (2016) Comparative analysis of the extreme temperature event change over 488 Northeast China and Hokkaido, Japan from 1951 to 2011. Theor Appl Climatol 124:375-384.

489 Wang Y, Sun Y, Hu T, Qin D, Song L (2018) Attribution of temperature changes in Western China. Int J 490 Climatol 38:742-750.

491 Weller E, Min SK, Palmer MD, Lee D, Yim BY, Yeh SW (2016) Multi-model attribution of upper-ocean temperature changes using an isothermal approach. Sci Rep 6:1-10. 
$494 \mathrm{Xu}$ Y, Gao X, Shi Y, Botao Z (2015) Detection and attribution analysis of annual mean temperature changes in 495 China. Clim Res 63:61-71.

496 Xuejie G, Zongci Z, Giorgi F (2002) Changes of extreme events in regional climate simulations over East Asia. Adv 497 Atmos Sci 19:927-942.

498 Yin H, Sun Y, Wan H, Zhang X, Lu C (2017) Detection of anthropogenic influence on the intensity of extreme 499 temperatures in China. Int J Climatol 37:1229-1237.

500 Yoon D, Cha DH, Lee G, Park C, Lee MI, Min KH (2018) Impacts of synoptic and local factors on heat wave events 501 over southeastern region of Korea in 2015. J Geophys Res: Atmos 123:12-081.

502 Yoon D, Cha DH, Lee MI, Min KH, Kim J, Jun SY, Choi Y (2020) Recent changes in heatwave characteristics over 503 Korea. Climate Dynamics 55:1685-1696.

504 Zeng Y, Zhou Z, Yan Z, Teng M, Huang C (2019) Climate change and its attribution in three gorges reservoir area, 505 China. Sustainability 11:7206.

506 Zhang J, Zhao T, Dai A, Zhang W (2019) Detection and attribution of atmospheric precipitable water changes since 507 the 1970s over China. Sci Rep 9:1-10.

508 Zhou L, Dickinson RE, Tian Y, Fang J, Li Q, Kaufmann RK (2004) Evidence for a significant urbanization effect on 509 climate in China. Proc Natl Acad Sci 101:9540-9544. 

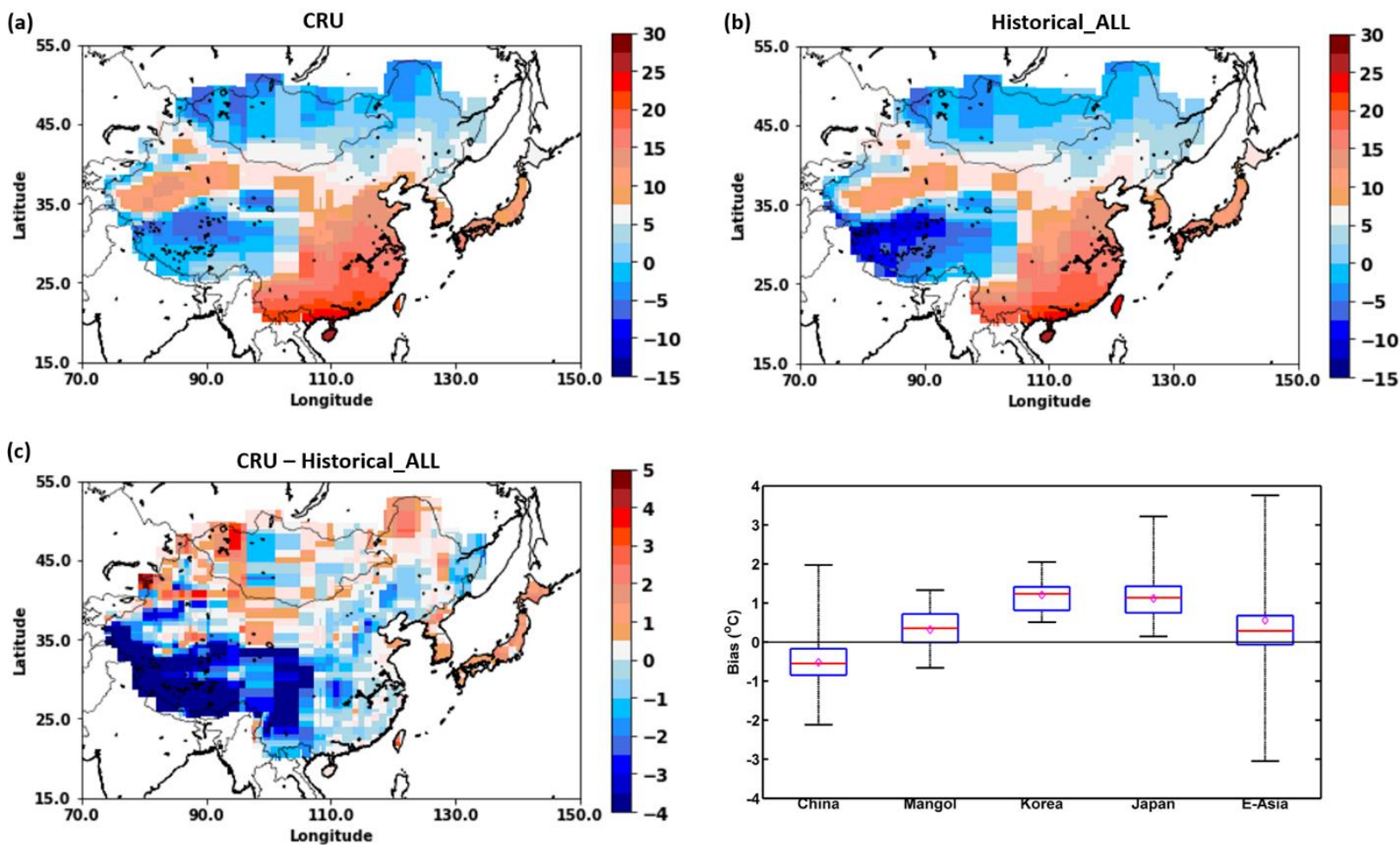

Fig. 1 Annual mean temperatures from 1901 to 2014. (a) CRU, (b) Multi-model ensemble mean of surface air temperature responses to ALL (anthropogenic and natural) forcing obtained from CMIP6. (c) Bias between CRU and CMIP6 (CMIP6 - CRU) across EA. (d) Bias (CMIP6 - CRU) boxplots showing 5\%, 25\%, mean (diamond), 75\%, and $95 \%$ values 
(a)

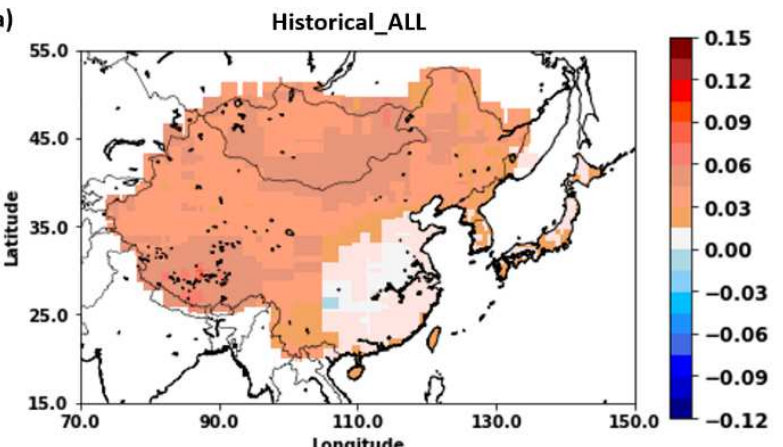

(c)

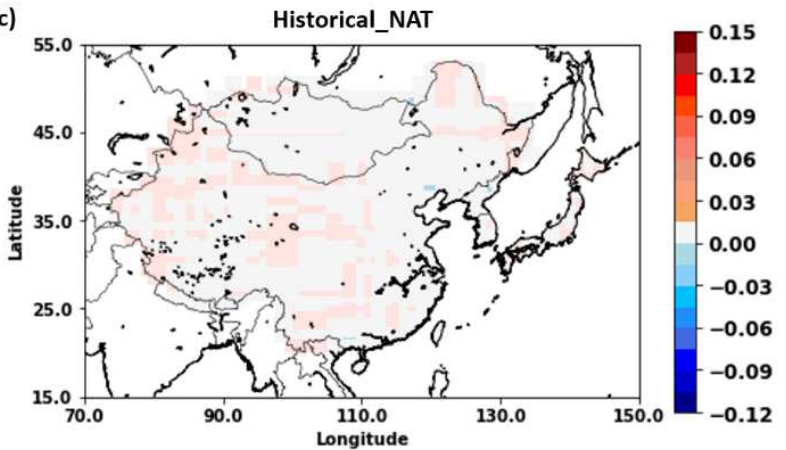

(b)

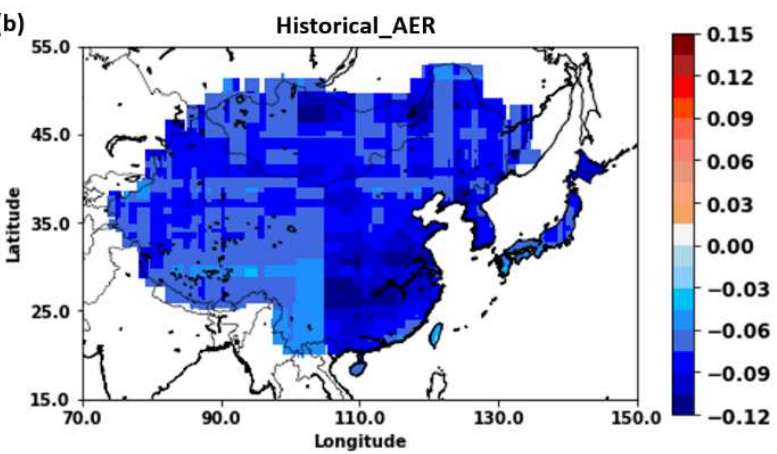

(d)

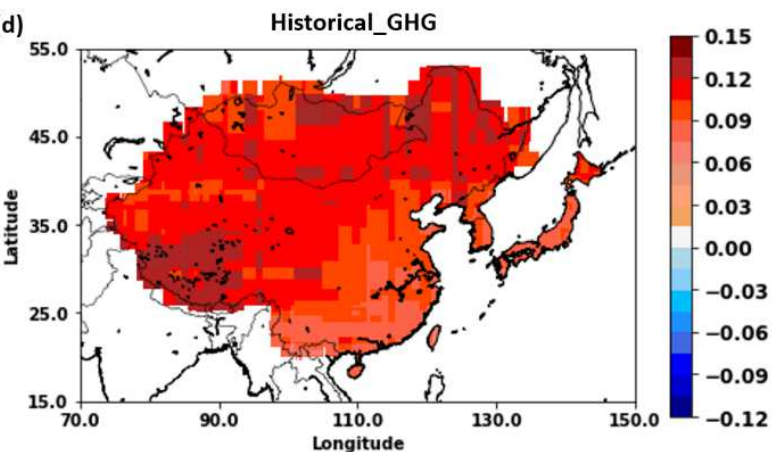

(e)

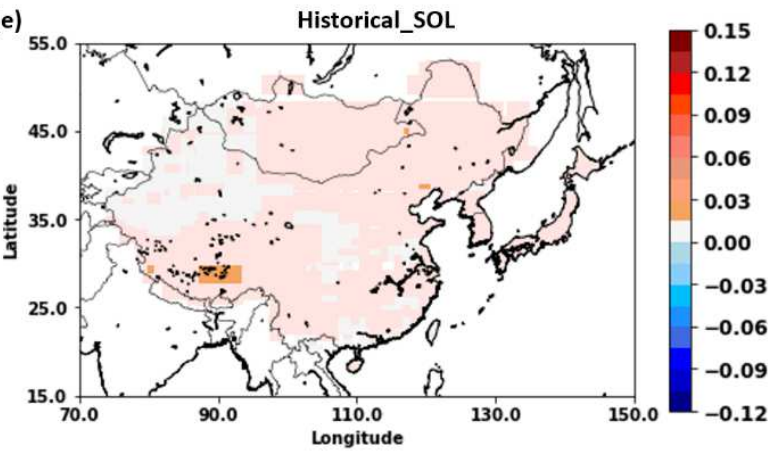

Fig. 2 Spatial distribution of trends in annual mean surface air temperature responses to different forcings $\left({ }^{\circ} \mathrm{C} /\right.$ decade $)$ for the historical period 1850-2014. (a) all (ALL), (b) anthropogenic aerosol (AER), (c) natural (NAT), (d) greenhouse gas (GHG), and (e) solar irradiance (SOL) forcings. The trends are estimated based on robust regression analysis 

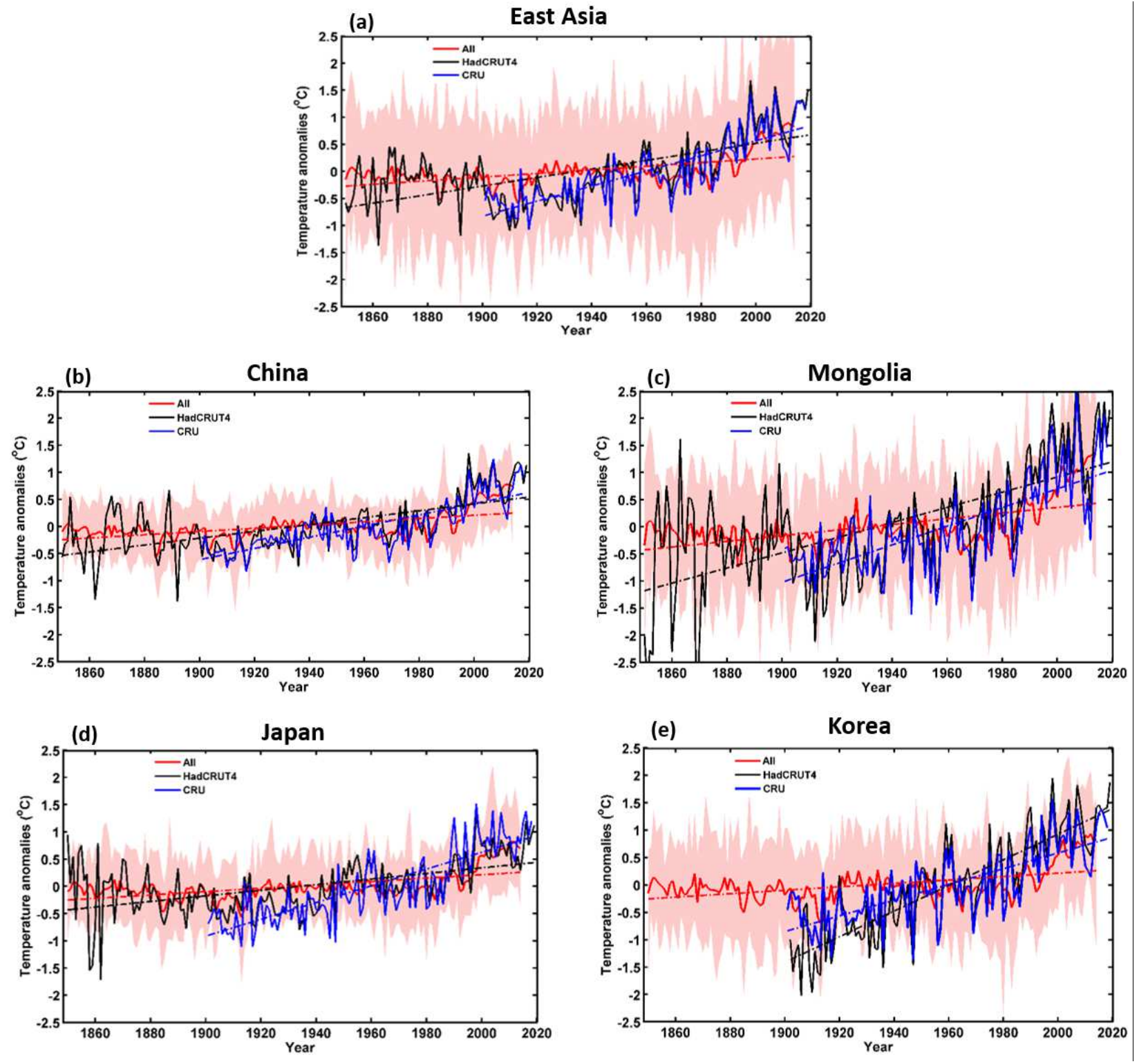

Fig. 3 Temporal variation of annual mean temperature anomaly responses to ALL (all forcings) averaged across East Asia and individual countries from observations (CRU and HadCRUT4) and multi-model mean simulations (CMIP6) for the period 1850-2014 (CRU: 1901-2018, HadCRUT4: 1850-2019). Shaded bands are multi-model ranges 

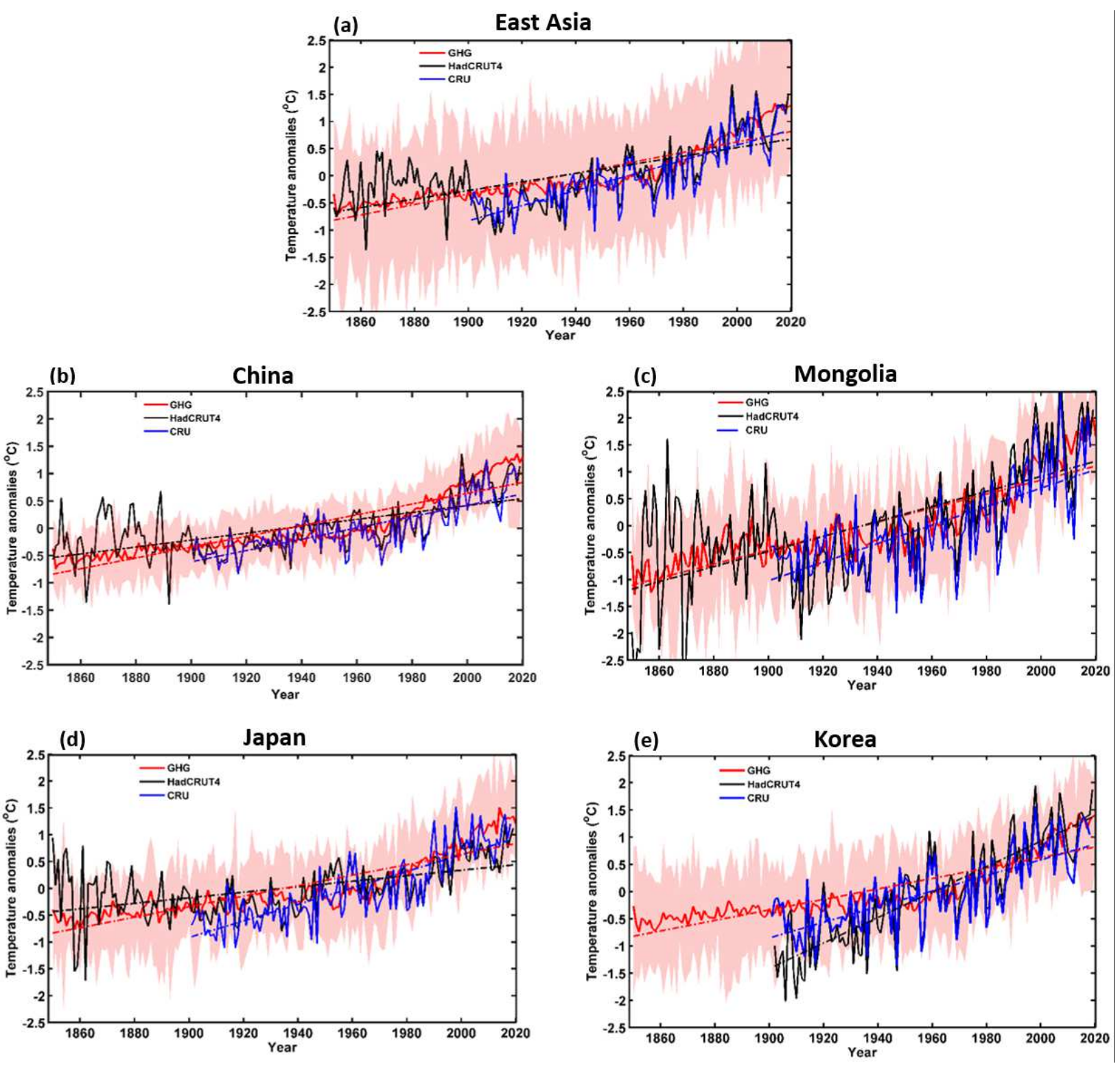

Fig. 4 As for Figure 3 but showing temperature anomaly responses to GHG forcing 

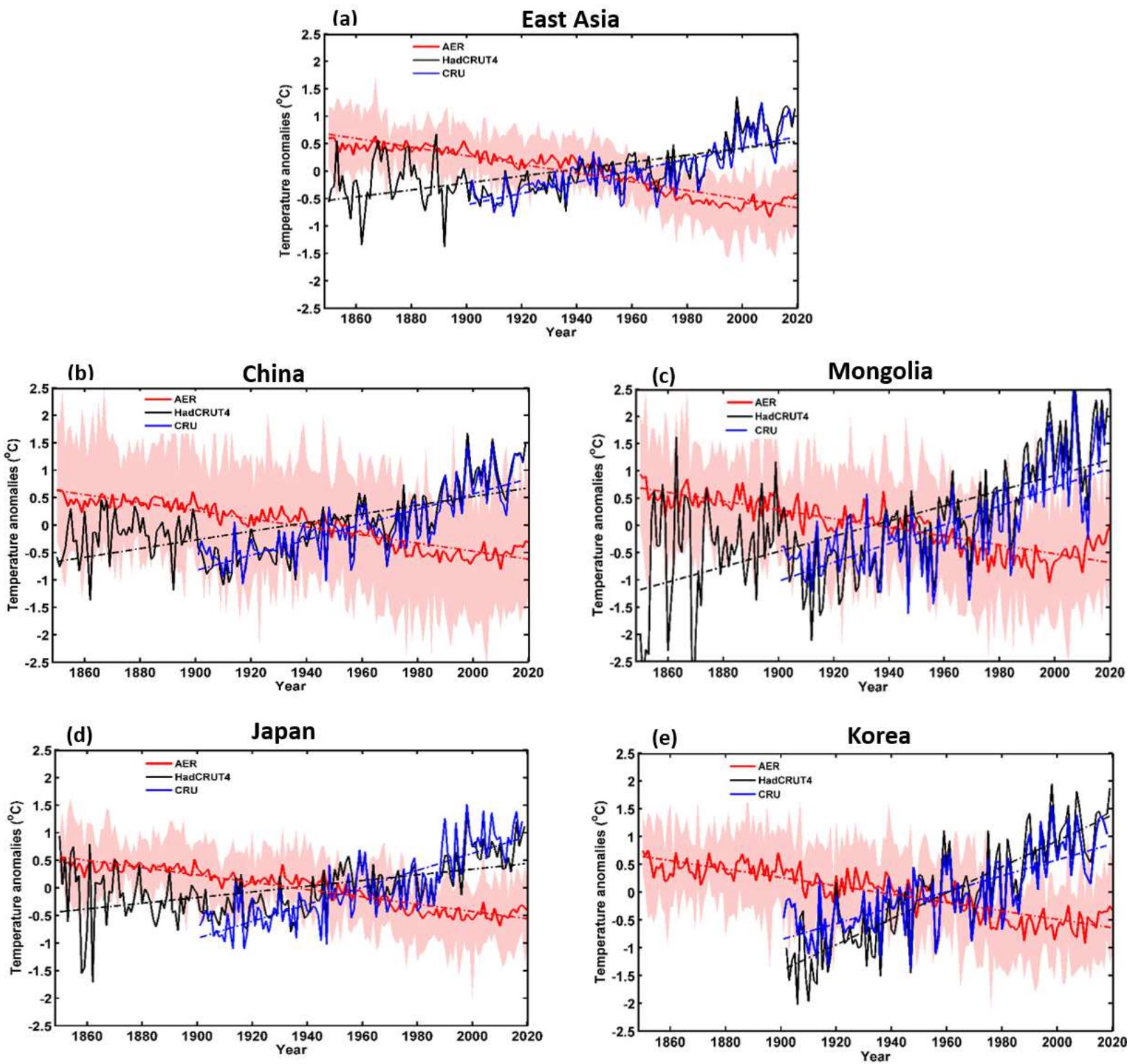

Fig. 5 As for Figure 3 but showing temperature anomaly responses to aerosol (AER) forcing 

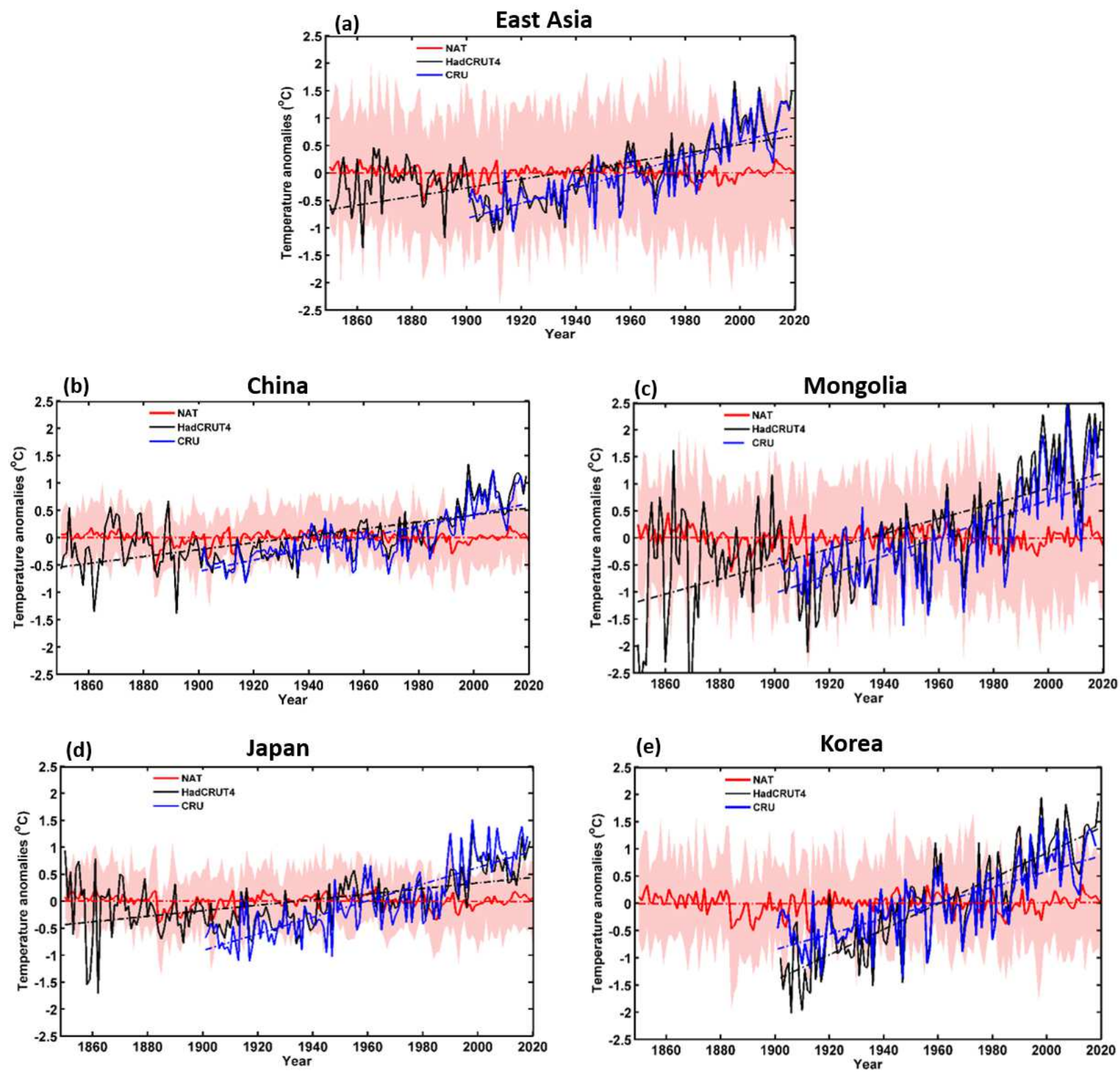

Fig. 6 As for Figure 3 but showing temperature anomaly responses to natural (NAT) forcing 

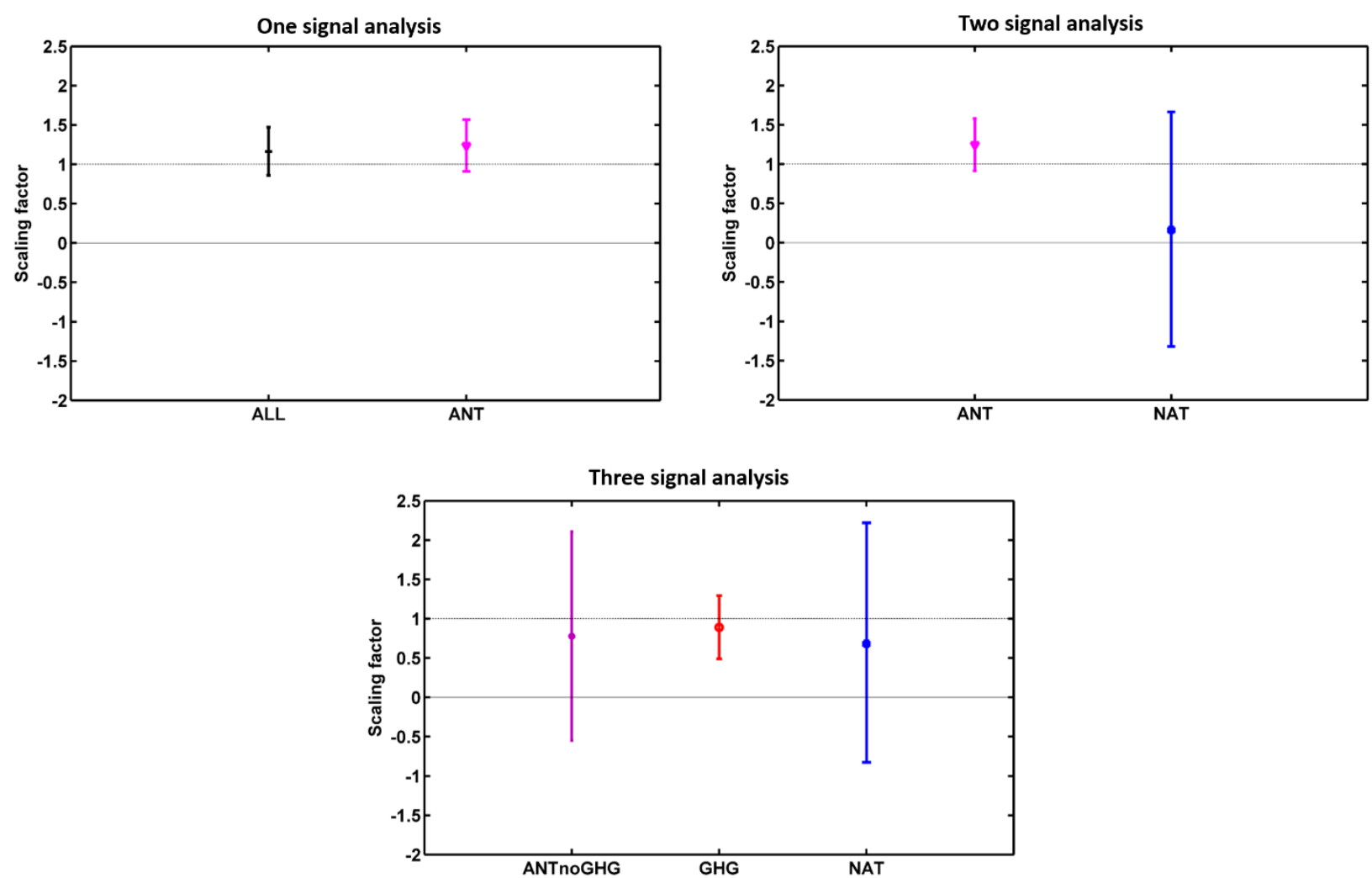

565 Fig. 7 Best estimates of the scaling factors using the regularized optimal fingerprinting method with $90 \%$ confidence intervals over EA for the period 1905-2014. (a) One-signal analysis of all (ALL) and anthropogenic aerosols (ANT) forcings, (b) two-signal analysis of ANT and NAT forcings, (c) three-signal analysis of ANTnoGHG, GHG, and NAT 

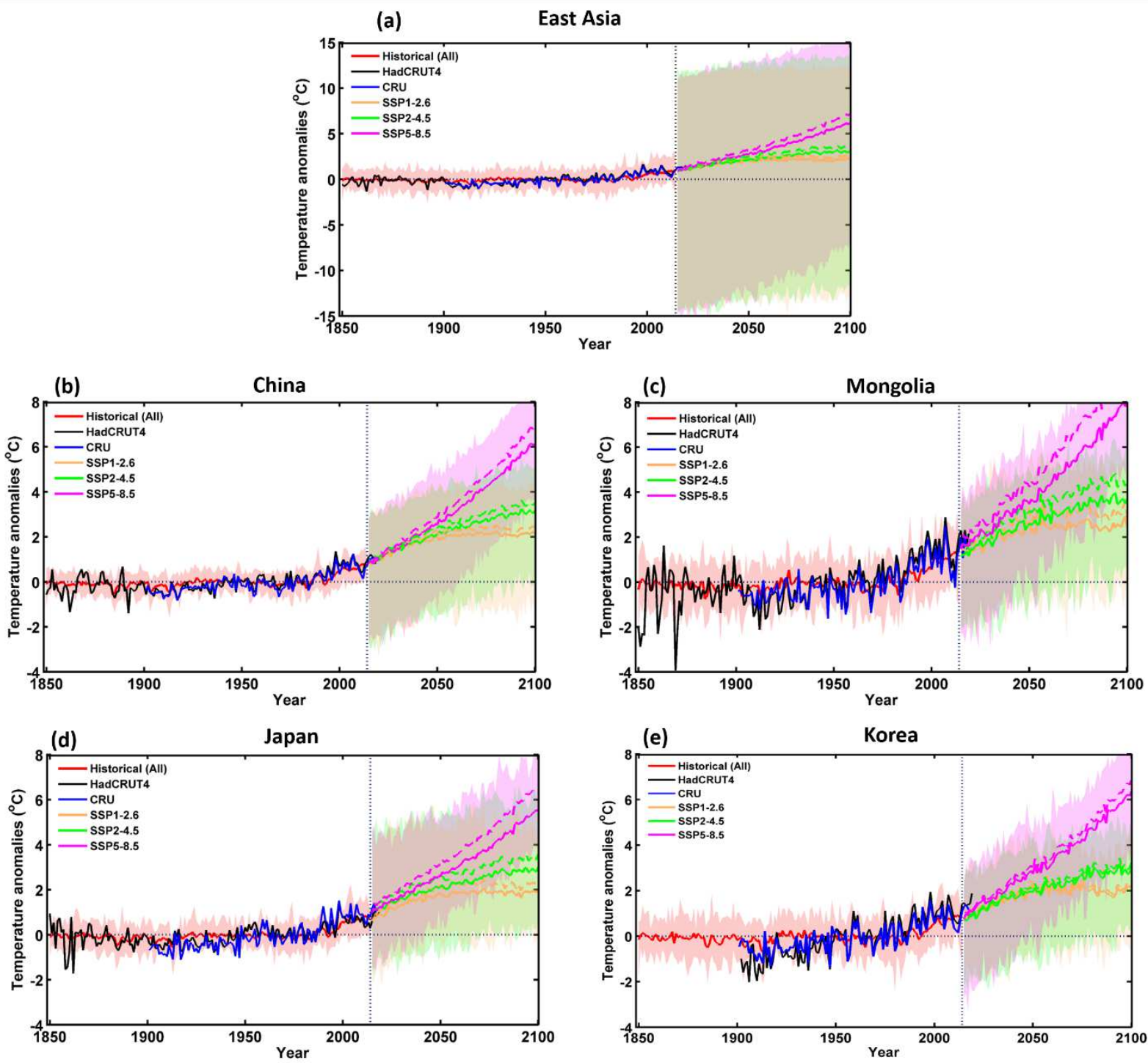

Fig. 8 Temporal variations in annual SAT anomalies (relative to 1995-2014) during the period 1850-2100. Shaded bands are the multi-model ranges. Future projections are based on the multi-model ensemble means under SSP1-2.6 (gold line), SSP2-4.5 (green line), and SSP5-8.5 (magenta line). The dashed lines indicate best-estimate observationconstrained future temperature projections for (a) East Asia, (b) China, (c) Mongolia, (d) Japan, and (e) Korea 
Table 1 Models used in the study for historical and future projections ( $\mathrm{Y}=$ 'yes' and ' $\mathrm{N}$ ' $=$ no). The numbers in parenthesis represent the ensemble sizes of the corresponding models

\begin{tabular}{|c|c|c|c|c|c|c|c|c|c|c|}
\hline \multirow[t]{2}{*}{$\begin{array}{l}\text { Model } \\
\text { name }\end{array}$} & \multicolumn{6}{|c|}{ Historical forcing (1850-2014) } & \multicolumn{3}{|c|}{$\begin{array}{c}\text { Future projection (2014- } \\
\mathbf{2 1 0 0})\end{array}$} & \multirow{2}{*}{$\begin{array}{c}\begin{array}{c}\text { Control } \\
\text { simulat } \\
\text { ions }\end{array} \\
\text { CTL }\end{array}$} \\
\hline & ALL & AER & NAT & GHG & SOL & LU & $\begin{array}{l}\text { SSP1- } \\
2.6\end{array}$ & $\begin{array}{l}\text { SSP2- } \\
4.5\end{array}$ & $\begin{array}{l}\text { SSP5- } \\
8.5\end{array}$ & \\
\hline $\begin{array}{l}\text { CNRM- } \\
\text { CM6-1-HR }\end{array}$ & $\mathrm{Y}(1)$ & $\mathrm{N}$ & $\mathrm{N}$ & $\mathrm{N}$ & $\mathrm{N}$ & $\mathrm{N}$ & $\mathrm{Y}(1)$ & $\mathrm{Y}(1)$ & $\mathrm{Y}(1)$ & $\mathrm{N}$ \\
\hline $\begin{array}{l}\text { CESM2- } \\
\text { WACCM }\end{array}$ & $\mathrm{Y}(4)$ & $\mathrm{N}$ & $\mathrm{N}$ & Y (3) & $\mathrm{N}$ & $\mathrm{Y}(1)$ & $\mathrm{Y}(1)$ & $\mathrm{Y}(4)$ & $\mathrm{Y}(3)$ & $\mathrm{Y}(8)$ \\
\hline E3SM-1-0 & Y (5) & $\mathrm{N}$ & $\mathrm{N}$ & $\mathrm{N}$ & $\mathrm{N}$ & $\mathrm{N}$ & $\mathrm{N}$ & $\mathrm{N}$ & $\mathrm{N}$ & $\mathrm{N}$ \\
\hline $\begin{array}{l}\text { BCC- } \\
\text { CSM2-MR }\end{array}$ & Y (3) & Y (3) & Y (3) & Y (3) & $\mathrm{N}$ & $\mathrm{N}$ & $\mathrm{N}$ & $\mathrm{N}$ & $\mathrm{N}$ & Y (15) \\
\hline $\begin{array}{l}\text { MRI-ESM2- } \\
0\end{array}$ & Y (5) & Y (5) & Y (5) & Y (5) & Y (4) & $\mathrm{N}$ & $\mathrm{Y}(1)$ & Y (5) & $\mathrm{Y}(1)$ & $\mathrm{Y}(8)$ \\
\hline CIESM & $\mathrm{Y}(3)$ & $\mathrm{N}$ & $\mathrm{N}$ & $\mathrm{N}$ & $\mathrm{N}$ & $\mathrm{N}$ & $\mathrm{N}$ & $\mathrm{N}$ & $\mathrm{N}$ & Y (20) \\
\hline $\begin{array}{l}\text { CAMS- } \\
\text { CSM1-0 }\end{array}$ & Y (3) & $\mathrm{N}$ & $\mathrm{N}$ & $\mathrm{N}$ & $\mathrm{N}$ & $\mathrm{N}$ & $\mathrm{N}$ & $\mathrm{N}$ & $\mathrm{N}$ & Y (16) \\
\hline INM-CM4-8 & Y (1) & $\mathrm{N}$ & $\mathrm{N}$ & $\mathrm{N}$ & $\mathrm{N}$ & $\mathrm{N}$ & Y (1) & Y (1) & $\mathrm{Y}(1)$ & $\mathrm{Y}(12)$ \\
\hline $\begin{array}{l}\text { FIO-ESM-2- } \\
0\end{array}$ & Y (3) & $\mathrm{N}$ & $\mathrm{N}$ & $\mathrm{N}$ & $\mathrm{N}$ & $\mathrm{N}$ & $\mathrm{N}$ & $\mathrm{N}$ & $\mathrm{N}$ & $Y(15)$ \\
\hline $\begin{array}{l}\text { CMCC- } \\
\text { CM2 }\end{array}$ & Y (3) & $\mathrm{N}$ & $\mathrm{N}$ & $\mathrm{N}$ & $\mathrm{N}$ & $\mathrm{N}$ & $\mathrm{N}$ & $\mathrm{N}$ & $\mathrm{N}$ & Y (12) \\
\hline $\begin{array}{l}\text { HADGEM3- } \\
\text { GC31-MM }\end{array}$ & Y (6) & $\mathrm{N}$ & $\mathrm{N}$ & $\mathrm{N}$ & $\mathrm{N}$ & $\mathrm{N}$ & Y (1) & $\mathrm{N}$ & Y (4) & Y (16) \\
\hline MIROC6 & Y (9) & Y (4) & $\mathrm{Y}(7)$ & Y (3) & Y (3) & Y (1) & Y (9) & $\mathrm{N}$ & Y (9) & $\mathrm{N}$ \\
\hline $\begin{array}{l}\text { GISS-E2-1- } \\
\text { G }\end{array}$ & $Y(8)$ & $Y(6)$ & $Y(5)$ & $Y(5)$ & Y (6) & Y (5) & Y (5) & Y (6) & $\mathrm{Y}(2)$ & $\mathrm{Y}(12)$ \\
\hline $\begin{array}{l}\text { CNRM- } \\
\text { CM6-1 }\end{array}$ & Y (6) & $\mathrm{N}$ & Y (4) & Y (9) & $\mathrm{N}$ & Y (1) & Y (4) & Y (5) & $\mathrm{Y}(5)$ & Y (20) \\
\hline $\begin{array}{l}\text { IPSL- } \\
\text { CM6A-LR }\end{array}$ & Y (4) & Y (9) & Y (9) & Y (4) & $\mathrm{N}$ & $\mathrm{Y}(1)$ & Y (3) & $\mathrm{N}$ & Y (6) & Y (6) \\
\hline $\begin{array}{l}\text { CNRM- } \\
\text { ESM2-1 }\end{array}$ & Y (3) & Y (2) & $\mathrm{N}$ & $\mathrm{N}$ & $\mathrm{N}$ & Y (1) & Y (4) & Y (5) & Y (4) & Y (16) \\
\hline $\begin{array}{l}\text { ACCESS- } \\
\text { CM2 }\end{array}$ & Y (3) & $\mathrm{N}$ & $\mathrm{N}$ & $\mathrm{N}$ & $\mathrm{N}$ & $\mathrm{N}$ & Y (3) & Y (3) & Y (3) & $\mathrm{N}$ \\
\hline $\begin{array}{l}\text { ACCESS- } \\
\text { ESM1-5 }\end{array}$ & Y (6) & Y (3) & Y (3) & Y (3) & $\mathrm{N}$ & $\mathrm{N}$ & Y (5) & Y (6) & Y (3) & $\mathrm{N}$ \\
\hline
\end{tabular}




\begin{tabular}{|l|l|l|l|l|l|l|l|l|l|l|}
\hline $\begin{array}{l}\text { HadGEM3- } \\
\text { GC31-LL }\end{array}$ & $\mathrm{Y}(4)$ & $\mathrm{Y}(4)$ & $\mathrm{Y}(4)$ & $\mathrm{Y}(4)$ & $\mathrm{N}$ & $\mathrm{N}$ & $\mathrm{Y}(1)$ & $\mathrm{Y}(4)$ & $\mathrm{Y}(4)$ & $\mathrm{Y}(12)$ \\
\hline $\begin{array}{l}\text { UKESM1-0- } \\
\text { LL }\end{array}$ & $\mathrm{Y}(6)$ & $\mathrm{N}$ & $\mathrm{N}$ & $\mathrm{N}$ & $\mathrm{N}$ & $\mathrm{N}$ & $\mathrm{Y}(4)$ & $\mathrm{Y}(6)$ & $\mathrm{Y}(3)$ & $\mathrm{Y}(10)$ \\
\hline CanESM5 & $\mathrm{Y}(5)$ & $\mathrm{Y}(9)$ & $\mathrm{Y}(5)$ & $\mathrm{Y}(6)$ & $\mathrm{Y}(9)$ & $\mathrm{N}$ & $\mathrm{Y}(3)$ & $\mathrm{Y}(5)$ & $\mathrm{Y}(4)$ & $\mathrm{N}$ \\
\hline $\begin{array}{l}\text { GFDL- } \\
\text { ESM4 }\end{array}$ & $\mathrm{N}$ & $\mathrm{Y}(1)$ & $\mathrm{Y}(3)$ & $\mathrm{Y}(1)$ & $\mathrm{N}$ & $\mathrm{N}$ & $\mathrm{N}$ & $\mathrm{Y}(3)$ & $\mathrm{N}$ & $\mathrm{N}$ \\
\hline $\begin{array}{l}\text { CMCC- } \\
\text { ESM2 }\end{array}$ & $\mathrm{N}$ & $\mathrm{N}$ & $\mathrm{N}$ & $\mathrm{N}$ & $\mathrm{N}$ & $\mathrm{Y}(1)$ & $\mathrm{N}$ & $\mathrm{N}$ & $\mathrm{N}$ & $\mathrm{Y}(16)$ \\
\hline $\begin{array}{l}\text { MPI-ESM1- } \\
\text { 2-LR }\end{array}$ & $\mathrm{N}$ & $\mathrm{N}$ & $\mathrm{N}$ & $\mathrm{N}$ & $\mathrm{N}$ & $\mathrm{Y}(2)$ & $\mathrm{Y}(5)$ & $\mathrm{Y}(4)$ & $\mathrm{Y}(3)$ & $\mathrm{Y}(18)$ \\
\hline $\begin{array}{l}\text { CESM2 } \\
\text { FGOALS- } \\
\text { f3-L }\end{array}$ & $\mathrm{N}$ & $\mathrm{N}$ & $\mathrm{N}$ & $\mathrm{N}$ & $\mathrm{N}$ & $\mathrm{N}$ & $\mathrm{Y}(3)$ & $\mathrm{Y}(3)$ & $\mathrm{Y}(3)$ & $\mathrm{Y}(20)$ \\
\hline $\begin{array}{l}\text { NESM3 } \\
\text { KACE-1-0- } \\
\text { G }\end{array}$ & $\mathrm{N}$ & $\mathrm{N}$ & $\mathrm{N}$ & $\mathrm{N}$ & $\mathrm{N}$ & $\mathrm{N}$ & $\mathrm{N}$ & $\mathrm{Y}(3)$ & $\mathrm{N}$ & $\mathrm{Y}(8)$ \\
\hline \begin{tabular}{l} 
Total \\
\hline
\end{tabular} & $21(91)$ & $10(46)$ & $10(48)$ & $11(46)$ & $4(22)$ & $8(13)$ & $17(54)$ & $18(67)$ & $17(59)$ & $\begin{array}{l}21 \\
(283)\end{array}$ \\
\hline
\end{tabular}

602

603

604

605

606

607

608

609

610

611

612

613

614

615

616

617

618 
641

642

643

644

645

646

647

648

649

650
Table 2 Annual mean surface air temperature trend $\left({ }^{\circ} \mathrm{C} / \mathrm{decade}\right)$ responses to different forcings in each East Asian country and the entire EA region for the period 1850-2014 (P1) and 1971-2014 (P2, after third industrial revolution, shown in parenthesis). ALL = all, AER = anthropogenic aerosol, NAT = natural, GHG = greenhouse gas, $\mathrm{SOL}=\mathrm{solar}$ irradiance, and LU = land use forcings

\begin{tabular}{|l|l|l|l|l|l|}
\hline $1850-2014$ & East Asia & China & Mongolia & Japan & Korea \\
\hline ALL & & & & \\
& $\begin{array}{l}0.031 \\
(0.255)\end{array}$ & $\begin{array}{l}0.027 \\
(0.223)\end{array}$ & $\begin{array}{l}0.049 \\
(0.379)\end{array}$ & $\begin{array}{l}0.026 \\
(0.25)\end{array}$ & $\begin{array}{l}0.029 \\
(0.266)\end{array}$ \\
\hline AER & -0.076 & -0.081 & -0.086 & -0.068 & -0.078 \\
& $(-0.035)$ & $(-0.058)$ & $(0.010)$ & $(-0.036)$ & $(-0.041)$ \\
\hline NAT & -0.003 & -0.0012 & -0.002 & -0.002 & -0.002 \\
& $(0.019)$ & $(0.013)$ & $(0.020)$ & $(0.015)$ & $(0.036)$ \\
\hline GHG & 0.082 & 0.090 & 0.1106 & 0.077 & 0.087 \\
& $(0.268)$ & $(0.27)$ & $(0.328)$ & $(0.240)$ & $(0.278)$ \\
\hline SOL & 0.005 & & & 0.005 & 0.005 \\
& $(0.008)$ & $(-0.001)$ & $(0.007)$ & $(0.009)$ & $(0.029)$ \\
\hline LU & & & 0.079 & 0.077 & 0.096 \\
& 0.084 & 0.069 & $(0.327)$ & $(0.200)$ & $(0.218)$ \\
\hline
\end{tabular}


651

652

653

654

\begin{tabular}{|l|l|l|l|l|l|}
\hline & $\begin{array}{l}\text { East Asia } \\
(\text { CRU) }\end{array}$ & $\begin{array}{l}\text { China } \\
(\text { CRU) }\end{array}$ & $\begin{array}{l}\text { Mongolia } \\
\text { (CRU) }\end{array}$ & $\begin{array}{l}\text { Japan } \\
\text { (CRU) }\end{array}$ & $\begin{array}{l}\text { Korea } \\
\text { (CRU) }\end{array}$ \\
\hline ALL & 0.69 & 0.76 & 0.62 & 0.70 & 0.53 \\
\hline AER & -0.68 & -0.66 & -0.55 & -0.70 & 0.55 \\
\hline NAT & 0.03 & 0.05 & -0.03 & 0.01 & 0.06 \\
\hline GHG & 0.77 & 0.77 & 0.70 & 0.75 & 0.65 \\
\hline SOL & 0.08 & 0.10 & 0.006 & 0.09 & 0.04 \\
\hline LU & & 0.96 & 0.97 & 0.95 & 0.96 \\
\hline
\end{tabular}

Table 3 Correlations between surface air temperature (SAT) in observed data (CRU) and SAT responses to different forcings in CMIP historical models. ALL = all, AER = anthropogenic aerosol, NAT = natural, GHG = greenhouse gas, $\mathrm{SOL}=$ solar irradiance, and LU = land use forcings

655

656

657

658

659

660

661

662

663

664

665

666

667

668

669

670

671 
672 Table 4 Best-estimate scaling factors and 90\% confidence intervals (shown in parenthesis) of ALL (anthropogenic

673 and natural) forcing, estimated from one-signal analysis, in East Asian countries for the period 1905-2014

\begin{tabular}{|c|l|l|l|l|l|}
\hline $\begin{array}{c}\mathbf{1 9 0 5}- \\
\mathbf{2 0 1 4}\end{array}$ & \multicolumn{1}{|c|}{$\begin{array}{c}\text { East Asia } \\
(\mathbf{9 0 \%})\end{array}$} & \multicolumn{1}{|c|}{$\begin{array}{c}\text { China } \\
\mathbf{( 9 0 \% )}\end{array}$} & \multicolumn{1}{|c|}{$\begin{array}{c}\text { Mongolia } \\
\mathbf{( 9 0 \% )}\end{array}$} & \multicolumn{1}{|c|}{$\begin{array}{c}\text { Japan } \\
\mathbf{( 9 0 \% )}\end{array}$} & \multicolumn{1}{|c|}{$\begin{array}{c}\text { Korea } \\
\mathbf{( 9 0 \% )}\end{array}$} \\
\hline ALL & 1.16 & 1.11 & 1.22 & 1.19 & 1.08 \\
& $(0.85-1.47)$ & $(0.85-1.38)$ & $(1.01-1.44)$ & $(0.86-1.51)$ & $(0.71-1.45)$ \\
\hline
\end{tabular}

674

675

676

677

678

679

680

681

682

683

684

685

686

687

688

689

690

691

692

693

694

695

696

697

698

699 
Table 5 Best-estimates and 90\% confidence intervals (shown in parenthesis) of future scenarios (SSP1-2.6, SSP2-4.5, 701 and SSP5-8.5) in East Asian countries

\begin{tabular}{|c|c|c|c|c|c|c|}
\hline $\begin{array}{c}\text { Future } \\
\text { scenarios }\end{array}$ & Year & $\begin{array}{c}\text { East Asia } \\
(90 \%)\end{array}$ & $\begin{array}{l}\text { China } \\
(90 \%)\end{array}$ & $\begin{array}{c}\text { Mongolia } \\
(90 \%)\end{array}$ & $\begin{array}{l}\text { Japan } \\
(90 \%)\end{array}$ & $\begin{array}{l}\text { Korea } \\
(90 \%)\end{array}$ \\
\hline \multirow[t]{3}{*}{ SSP1-2.6 } & 2050 & $\begin{array}{c}2.32 \\
(1.80-3.15)\end{array}$ & $\begin{array}{c}2.22 \\
(1.57-2.87)\end{array}$ & $\begin{array}{c}3.22 \\
(2.38-4.07)\end{array}$ & $\begin{array}{c}2.2 \\
(1.63-2.76)\end{array}$ & $\begin{array}{c}2.36 \\
(1.71-3.01)\end{array}$ \\
\hline & 2070 & $\begin{array}{c}2.64 \\
(1.97-3.29)\end{array}$ & $\begin{array}{c}2.46 \\
(1.79-3.13)\end{array}$ & $\begin{array}{c}3.31 \\
(2.51-4.12)\end{array}$ & $\begin{array}{c}2.3 \\
(1.79-2.8)\end{array}$ & $\begin{array}{c}2.54 \\
(1.88-3.2)\end{array}$ \\
\hline & 2100 & $\begin{array}{c}2.49 \\
(1.84-3.12)\end{array}$ & $\begin{array}{c}2.37 \\
(1.72-3.03)\end{array}$ & $\begin{array}{c}2.95 \\
(2.18-3.73)\end{array}$ & $\begin{array}{c}2.29 \\
(1.79-2.79)\end{array}$ & $\begin{array}{c}2.38 \\
(1.76-3.02)\end{array}$ \\
\hline \multirow[t]{3}{*}{ SSP2-4.5 } & 2050 & $\begin{array}{c}2.46 \\
(1.78-3.16)\end{array}$ & $\begin{array}{c}2.4 \\
(1.73-3.06)\end{array}$ & $\begin{array}{c}3.14 \\
(2.35-3.97)\end{array}$ & $\begin{array}{c}2.56 \\
(1.93-3.19)\end{array}$ & $\begin{array}{c}2.12 \\
(1.45-2.8)\end{array}$ \\
\hline & 2070 & $\begin{array}{c}3.10 \\
(2.34-3.89)\end{array}$ & $\begin{array}{c}3.01 \\
(2.26-3.76)\end{array}$ & $\begin{array}{c}4.09 \\
(3.14-5.07)\end{array}$ & $\begin{array}{c}3.01 \\
(2.38-3.64)\end{array}$ & $\begin{array}{c}2.72 \\
(1.94-3.5)\end{array}$ \\
\hline & 2100 & $\begin{array}{c}3.66 \\
(3.07-4.27)\end{array}$ & $\begin{array}{c}3.53 \\
(2.92-4.14)\end{array}$ & $\begin{array}{c}4.51 \\
(3.85-5.23)\end{array}$ & $\begin{array}{c}3.59 \\
(3.08-4.09)\end{array}$ & $\begin{array}{c}3.34 \\
(2.74-3.94)\end{array}$ \\
\hline \multirow[t]{3}{*}{ SSP5-8.5 } & 2050 & $\begin{array}{c}3.12 \\
(2.55-3.9)\end{array}$ & $\begin{array}{c}2.84 \\
(2.09-3.58)\end{array}$ & $\begin{array}{c}4.21 \\
(3.43-5.03)\end{array}$ & $\begin{array}{c}3.08 \\
(2.56-3.60)\end{array}$ & $\begin{array}{c}2.99 \\
(2.34-3.64)\end{array}$ \\
\hline & 2070 & $\begin{array}{c}4.61 \\
(4.17-5.28)\end{array}$ & $\begin{array}{c}4.44 \\
(3.81-5.08)\end{array}$ & $\begin{array}{c}6.22 \\
(5.55-6.97)\end{array}$ & $\begin{array}{c}4.27 \\
(3.87-4.68)\end{array}$ & $\begin{array}{c}4.3 \\
(3.8-4.83)\end{array}$ \\
\hline & 2100 & $\begin{array}{c}7.22 \\
(6.79-8.15)\end{array}$ & $\begin{array}{c}6.86 \\
(6.05-7.67)\end{array}$ & $\begin{array}{c}9.87 \\
(9.19-10.6)\end{array}$ & $\begin{array}{c}6.57 \\
(6.08-7.06)\end{array}$ & $\begin{array}{c}6.99 \\
(6.31-7.6)\end{array}$ \\
\hline
\end{tabular}




\section{Supplementary Files}

This is a list of supplementary files associated with this preprint. Click to download.

- SupplementaryMaterial.docx 